\title{
A TrkB/EphrinA Interaction Controls Retinal Axon Branching and Synaptogenesis
}

\author{
Katharine J. M. Marler, ${ }^{1}$ Elena Becker-Barroso, ${ }^{1 *}$ Albert Martínez, ${ }^{2 \star}$ Marta Llovera, ${ }^{3 *}$ Corinna Wentzel, ${ }^{1}$ \\ Subathra Poopalasundaram, ${ }^{1}$ Robert Hindges, ${ }^{1}$ Eduardo Soriano, ${ }^{2}$ Joan Comella,${ }^{3}$ and Uwe Drescher ${ }^{1}$ \\ ${ }^{1}$ Medical Research Council Centre for Developmental Neurobiology, King's College London, Guy's Campus, London SE1 1UL, United Kingdom, ${ }^{2}$ Institute \\ for Research in Biomedicine, Parc Científic de Barcelona, Department of Cell Biology, Faculty of Biology, University of Barcelona, and Centro de \\ Investigación en Red de Enfermedades Neurodegenerativas (Instituto de Salud Carlos III), 08028 Barcelona, Spain, and ${ }^{3}$ Cell Signalling and Apoptosis \\ Group, Departament de Ciències Mèdiques Bàsiques, Laboratori d’Investigació, Universitat de Lleida-Hospital Universitari Arnau de Vilanova, Institut de \\ Recerca Biomédica de Lleida, 25198 Lleida, Spain
}

Toward understanding topographically specific branching of retinal axons in their target area, we have studied the interaction between neurotrophin receptors and members of the Eph family. TrkB and its ligand BDNF are uniformly expressed in the retina and tectum, respectively, and exert a branch-promoting activity, whereas EphAs and ephrinAs are expressed in gradients in retina and tectum and can mediate a suppression of axonal branching. We have identified a novel cis interaction between ephrinA5 and TrkB on retinal ganglion cell axons. TrkB interacts with ephrinA5 via its second cysteine-rich domain (CC2), which is necessary and sufficient for binding to ephrinA5. Their functional interaction is twofold: ephrinA5 augments BDNF-promoted retinal axon branching in the absence of its activator EphA7-Fc, whereas EphA7-Fc application abolishes branching in a local and concentration-dependent manner. The importance of TrkB in this process is shown by the fact that overexpression of an isolated TrkB-CC2 domain interfering with the ephrin $\mathrm{A} / \mathrm{TrkB}$ interaction abolishes this regulatory interplay, whereas knockdown of TrkB via RNA interference diminishes the ephrinA5-evoked increase in branching. The ephrinA/Trk interaction is neurotrophin induced and specifically augments the PI-3 kinase/Akt pathway generally known to be involved in the promotion of branching. In addition, ephrinAs/TrkB modulate axon branching and also synapse formation of hippocampal neurons. Our findings uncover molecular mechanisms of how spatially restricted axon branching can be achieved by linking globally expressed branch-promoting with differentially expressed branch-suppressing activities. In addition, our data suggest that growth factors and the EphA-ephrinA system interact in a way that affects axon branching and synapse development.

Key words: axon guidance; BDNF; retinotectal; EphA/ephrinA; topography; neurotrophin

\section{Introduction}

During development of the nervous system, precisely ordered neuronal connections are formed in a gradual, stepwise process. In the chick and mouse retinotectal/collicular projection, for example, retinal ganglion cell axons grow into the tectum/superior colliculus (SC) in a mostly nontopographic manner and substantially overshoot their future termination zones (Nakamura and

\footnotetext{
Received Aug. 26, 2008; revised 0ct. 2, 2008; accepted 0ct. 6, 2008.

This work was supported by the Wellcome Trust, Biotechnology and Biological Sciences Research Council, and the Medical Research Council, as well as Ministerio de Educación y Ciencia (MEC) Grant SAF 2007-60287 and Generalitat de Catalunya to (J.C.), MEC Grant SAF2005-0171 (E.S.), Instituto de Salud Carlos III Grants PI04/2433 (A.M.) and P04/2537 (M.L.). M.L. holds a Ramon y Cajal research contract from the Spanish Ministry of Education and Science. We thank Naila Ben Fredj for help with hippocampal cell cultures and P. Gordon-Weeks, S. Guthrie, A. Püschel, C. Jarvis, and R. Drescher for helpful comments on this manuscript.

*E.B.B., A.M., and M.L. contributed equally to this work.

Correspondence should be addressed to Uwe Drescher, Medical Research Council Centre for Developmental Neurobiology, King's College London, New Hunt's House, Guy's Campus, London SE1 1UL, UK. E-mail: uwe.drescher@kcl.ac.uk.

E. Becker-Barroso's present address: The Lancet Neurology, 32 Jamestown Road, London NW1 7BY, UK.

J. Comella's present address: Institut de Neurociencies y Departament de Bioquímica, Universitat Autònoma de Barcelona, 08193 Cerdanyola del Valles, Spain.

DOI:10.1523/JNEUROSCI.1915-08.2008

Copyright $\odot 2008$ Society for Neuroscience $\quad$ 0270-6474/08/2812700-13\$15.00/0
}

O’Leary, 1989; Simon and O'Leary, 1992). A rough topographic map develops through axon branching and arborization at correct target sites, resulting in the formation of topographically appropriate but diffuse termination zones. In this process, temporal retinal axons form branches preferentially in the anterior tectum/SC, whereas nasal retinal axons branch in the posterior tectum/SC (for review, see McLaughlin and O'Leary, 2005). Subsequent maturation of the map occurs through large-scale elimination of ectopic branches and overshot axon segments, and the formation of dense termination zones, involving correlated neuronal activity (Ruthazer and Cline, 2004).

It is believed that the initial processes that ultimately lead to the formation of termination zones are controlled by an interplay between global branch-promoting activities and local branchsuppressing activities. The neurotrophin BDNF acting via the TrkB receptor is a good candidate for providing this growthpromoting activity. Injection of BDNF into the tectum of Xenopus laevis tadpoles increases the branching and complexity of retinal axon terminal arbors, whereas application of neutralizing antibodies to BDNF reduces axon arborization and complexity (Cohen-Cory and Fraser, 1995). However, neither BDNF in the tectum/SC nor TrkB in the retina is expressed in a gradient, in- 
dicating that the TrkB/BDNF system can provide permissive but not topographic guidance/branching information.

In contrast, members of the Eph family are expressed in gradients in the retina and tectum/SC and, with that, provide positional information with regard to the anteroposterior and dorsoventral axes. Data from in vitro and in vivo experiments indicate that the Eph family might exert its role in retinotectal mapping in higher vertebrates by controlling axon branching (for review, see McLaughlin and O'Leary, 2005).

Here we further characterize the "receptor" function of ephrinAs, that is, the expression of ephrinAs on retinal axons in a nasal $>$ temporal gradient, and of EphAs in the tectum/SC in an anterior $>$ posterior gradient. Our previous data derived from in vivo experiments indicated that activation of ephrinAs on retinal axons by tectally expressed EphA molecules results in a suppression of branching of nasal axons in the anterior tectum/SC, i.e., directing their branching to the posterior tectum/SC (Hornberger et al., 1999; Rashid et al., 2005). However, it was not clear how ephrinAs exert this effect, in particular because they are glycosylphosphatidylinositol (GPI)-anchored molecules requiring a transmembrane coreceptor for mediating their receptor function. By using biochemical approaches and various in vitro assays, we now provide evidence that ephrinAs suppress the branching of retinal axons by interacting in cis with TrkB.

It has been proposed that molecules involved in axon guidance and branching are used later to participate in synaptogenesis and synaptic plasticity, that is, molecules that control axon guidance and branching using attractive and repellent mechanisms mediate at later stages of development the formation, stabilization, and elimination of synapses (Klein, 2004; Ciani and Salinas, 2005). In support of this, our study of hippocampal neurons suggest that an TrkB/ephrinA interaction is involved here not only in the control of axon branching but also of synaptogenesis.

\section{Materials and Methods}

Reagents and antibodies. NGF (2.5S) was purchased from Alomone Labs. BDNF was purchased from Promega. The antibody anti-rat TrkA was from Upstate Biotechnology; anti-FLAG antibody was obtained from Affinity BioReagents or Sigma; anti-phospho-TrkA (Tyr490), antiphospho-phospholipase C $\gamma$ (PLC $\gamma$ ) (Tyr783), anti-phospho-p44/p42 mitogen-activated protein (MAP) kinase, and anti-phospho-Akt (Ser473) antibodies were from Cell Signaling Technology; anti-Akt (C20) antibody and anti-TrkB antibody were purchased from Santa Cruz Biotechnology; and anti- $\alpha$-tubulin antibody, goat anti-mouse IgG-HRP secondary antibody, anti-FLAG Affinity Gel, and Protein A-Sepharose were from Sigma. The secondary antibody goat anti-rabbit IgG-HRP was from GE Healthcare. The chemiluminescent substrates for developing Western blots were SuperSignal West Dura obtained from Pierce and EZ-ECL from Biological Industries. Laminin and all tissue culture reagents were from Invitrogen. Merosin was from Millipore. Recombinant EphA7-Fc chimera was obtained from R \& D Systems.

Cloning of chick TrkB $B^{F L A G}$ and deletion constructs. DNA encoding fulllength chick TrkB was obtained by reverse transcription-PCR using chick tectal cDNA as source. The sequence containing the mature protein (ASC .... WAV) was cloned into the expression vector $\beta C A$ (containing the chick $\beta$-actin promoter, signal peptide, and two FLAG tags). The deletion constructs were obtained by PCR from this original full-length clone. TrkB $\Delta 1$ starts from amino acid 139 (LSD...), TrkB $\Delta 2$ from amino acid 172 (QDI. . .), and $\operatorname{TrkB} \Delta 3$ from amino acid 195 (DLP... ). All clones were resequenced in full to verify they contained the original TrkB sequences. In case of TrkA and TrkC immunoprecipitations, clones isolated from rat cDNA libraries were used.

Cloning of Robo2-CC2 $2^{F L A G}$ and $C C 2^{F L A G}$. DNA encoding of Robo2 and of Robo2-CC2 ${ }^{\text {FLAG }}$ were cloned into $\beta C A$ (see above) via PCR using a plasmid containing human Robo2 (Hivert et al., 2002) as a template.
For Robo2-CC2 ${ }^{\text {FLAG }}$, the second cysteine-rich domain (CC2) of TrkB [amino acids 139-194 (LSD....PNC)] was inserted at amino acid position 637 of Robo2, i.e., between amino acids ..GDV and LVR. .. This site is located between the last (fifth) Ig domain and first fibronectin type III (FNIII) domain of Robo2, which positions the CC2 domain at approximately the same distance from the plasma membrane as it is in TrkB (two FNIII domains in Robo2, two Ig domains in TrkB). The resulting plasmid was resequenced verifying the original Robo 2 and CC2 sequences.

CC2 ${ }^{\text {FLAG }}$ comprising the amino acid sequences $139-194$ (see above) was cloned by PCR into the expression vector $\beta$ CA.

Cell culture and transfection. PC12 cells were obtained from Dr. Brian B. Rudkin (Lyon, France). This cell line was cultured as described previously (Egea et al., 2005). For experiments, PC12 cells were seeded in polyornithine-precoated $100 \mathrm{~mm}$ Petri dishes and left to adhere. Plasmid DNA containing ephrinA5 ${ }^{\text {FLAG }}$ was transfected with Lipofectamine 2000 reagent from Invitrogen, following the instructions of the manufacturer. In transient transfection experiments, cells were incubated for $48 \mathrm{~h}$ before treatment. Cells were serum deprived for $16 \mathrm{~h}$ and treated with NGF (50 ng/ml) for several time intervals, as indicated. Cell monolayer was washed twice with ice-cold PBS, and cells were lysed in either SDS lysis buffer (2\% SDS and $125 \mathrm{~mm}$ Tris-HCl, pH 6.8) to obtain total cell lysates or in a modified NP-40 lysis buffer when immunoprecipitation experiments were performed (see below for details). For the generation of stably expressing cells, the transfection was performed in $60 \mathrm{~mm}$ Petri dishes, and, $2 \mathrm{~d}$ later, cells were spitted and diluted (1:2 to 1:10) and selected using geneticin (G418) at $500 \mu \mathrm{g} / \mathrm{ml}$. After 3-4 weeks of selection, the resistant clones were picked up individually and allowed to grow until they were tested for ephrinA $5^{\mathrm{FLAG}}$ expression by Western blot. For generating pools of stably transformed PC12 cells, 3-4 weeks after selection, the resistant clones were pooled and allowed to grow until they were tested for ephrinA $5^{\text {FLAG }}$ expression by Western blot.

Immunoprecipitation and Western blot. PC12 transfected cells were treated with NGF for several time intervals and were lysed in a modified NP-40 lysis buffer (20 mm Tris, pH 7.4, $150 \mathrm{~mm} \mathrm{NaCl}, 2$ mм EDTA, 2 mм $\mathrm{MgCl}_{2}, 10 \%$ glycerol, $1 \mathrm{~mm}$ sodium orthovanadate, $25 \mathrm{~mm} \mathrm{NaF}, 40 \mathrm{~mm}$ $\beta$-glycerophosphate, $1 \%$ Triton X-100, and $1 \times$ EDTA-free Complete Protease inhibitor cocktail). After cell lysate clearing by centrifugation, protein was quantified from the supernatant by the Bio-Rad DC Protein assay kit. Approximately $1 \mathrm{mg}$ of total protein from each sample was incubated with $100 \mu \mathrm{l}$ of anti-FLAG M2 Affinity gel overnight at $4^{\circ} \mathrm{C}$ on an orbital shaker. Immunocomplexes were washed three times with lysis buffer, suspended in $20 \mu \mathrm{l}$ of Laemli's buffer, boiled, and loaded onto a $10 \%$ SDS-polyacrylamide gel. After gel electrophoresis and protein transfer to polyvinylidene difluoride membranes, blots were immunodetected with anti-rat TrkA antibodies (1:1000) and developed with EZECL. Membranes were stripped and reprobed with anti-FLAG antibody to check for equal immunoprecipitation efficiency. Western blot from total cell lysates was performed as described above, with $40 \mu \mathrm{g}$ of total protein per sample. Blots were immunodetected with anti-phospho-Akt (Ser473), anti-phospho-p44/42 MAP kinase (Thr202/Tyr204), antiphospho-TrkA (Y490), anti-phospho-PLC $\gamma$, anti-Akt (C-20), anti-rat TrkA, or anti- $\alpha$-tubulin. When necessary stripping of membranes was performed between immunodetections with $100 \mathrm{~mm}$ $\beta$-mercaptoethanol, $63.5 \mathrm{~mm}$ Tris-HCl, $\mathrm{pH} 6.8$, and 2\% SDS, for $30 \mathrm{~min}$ at $50^{\circ} \mathrm{C}$. Membranes were developed with EZ-ECL or SuperSignal West Dura, depending on the primary antibody used, and exposed to Fuji Super RX films. Densitometric analysis of films was performed with the Scion Image free software (Meyer Instruments).

Immunoprecipitations of TrkA, TrkB, TrkC, PDGF receptor, and TrkB deletions were performed as described by Carvalho et al. (2006).

Axon outgrowth and stripe assay. Single cells were prepared from the nasal third of embryonic day 8 (E8) chick retinas and electroporated with an enhanced green fluorescent protein (eGFP) expression construct to facilitate a later analysis of neurite outgrowth essentially as described by Carvalho et al. (2006), except cultures were plated on laminin-coated (10 $\mu \mathrm{g} / \mathrm{ml})$ and merosin-coated $(2 \mu \mathrm{g} / \mathrm{ml})$ dishes and cultured for $4 \mathrm{~d}$ in Neurobasal media with $2 \%$ B27 supplement, $1 \mathrm{~mm}$ glutamine, $5 \mu \mathrm{M}$ forskolin, and $1 \%$ penicillin/streptomycin solution. Use of forskolin results in an increase in cAMP levels in retinal axons, which correlates with 
an enhanced long-term survival via an increased surface localization of TrkB (MeyerFranke et al., 1995, 1998). Retinal ganglion cells (RGCs) were identified by staining for markers expressed on retinal axons such as TrkB, Brn3A, and Thy-I (Sheppard et al., 1991; Xiang et al., 1995; Garner et al., 1996). Routinely, those cells/axons with the longest axons were positive for these markers.

For the stripe assay, cells were plated on a substrate of alternating lanes of EphA7-Fc and Fc, or, as a control, $\mathrm{Fc}$ versus Fc. Protocols are described previously by Rashid et al. (2005) and Knöll et al. (2001a). One type of stripe in each setup was labeled by the addition of Fc-cyanine 3. Matrices generating $50-\mu \mathrm{m}$-wide stripes were used.

Cloning of RNA interference for knockdown of TrkB. Target sequences for RNA interference (RNAi) against TrkB were chosen according to Das et al. (2006). Target sequences for TrkB RNAi-1 were CTGTGAAATTATGTGGATTAA, for RNAi-3 were AGTCTGAATACATCTGTACTA, and for RNAi-4 were CGCCACAATATTGTTCTCAAA. Sequence for mutated RNAi-4* (see Fig. 2) is CGCCACAATATTTGTTCTCAAA-loop-TTTGAGAGCAATATTGTGGG. Mutations are shown in bold.

Organotypic slice cultures. Entorhinohippocampal slice cultures were prepared from newborn ephrinA $5^{-/-}$mice and control littermates, as well as OF-1 mice (Iffa Credo) as described previously (Del Río et al., 1997). Mice were anesthetized by hypothermia, their brains were removed, and the hippocampal formations were dissected out. Horizontal sections ( $350 \mu \mathrm{m}$ thick) were obtained using a Mcllwain tissue chopper. Selected slices were cultured using the interphase membrane method (Stoppini et al., 1991). A total of eight entorhinohippocampal cultures per condition were prepared from each animal type.

One microliter of the following solutions was applied on top of each slice at 4, 6, 8, and $11 \mathrm{~d}$ in vitro (DIV) after exchange of the medium. For the experiments performed with ephrinA $5^{-/-}$ mice and littermates, slices were treated with 1 $\mu \mathrm{l}$ of $0.1 \%$ BSA in $0.1 \mathrm{M}$ phosphate buffer (PB) as controls or $1 \mu \mathrm{l}$ of recombinant human BDNF (20 ng/ $\mu$; Millipore Bioscience Research

Reagents). In the experiments using OF-1 mice, organotypic slices were treated with $0.1 \%$ BSA in $0.1 \mathrm{M} \mathrm{PB}$ or Fc fragment $(5 \mu \mathrm{g} / \mathrm{ml})$ in PB-BSA as controls and with recombinant mouse EphA7-Fc chimera ( $5 \mu \mathrm{g} / \mathrm{ml}$; R \& D Systems) or recombinant human BDNF (20 ng/ $\mu$ l; Millipore Bioscience Research Reagents) in PB-BSA or with both solutions together.

Electron microscopy. After pharmacological treatments, 13 DIV cultures were fixed with $2 \%$ glutaraldehyde- $2 \%$ paraformaldehyde in $0.1 \mathrm{M}$ phosphate buffer, postfixed with $2 \%$ osmium tetroxide, and embedded in Araldite. Ultrathin sections were collected on Formvar-coated slot grids and stained with uranyl acetate and lead citrate. Electron micrographs covering $64 \mu \mathrm{m}^{2}$ (final magnification, 20,000 $\times$ ) were randomly taken from the stratum radiatum, and the number of synaptic contacts was counted $(n=$ 40-45 micrographs for group; two to three organotypic slice cultures per condition). Statistical analysis was performed using Student's $t$ test.

\section{Results}

\section{EphrinA activation abolishes BDNF-promoted branching of} retinal axons

We analyzed the effects of an interaction between ephrinAs and TrkB on the branching of retinal axons in a simple axon outmultiple-comparison test.
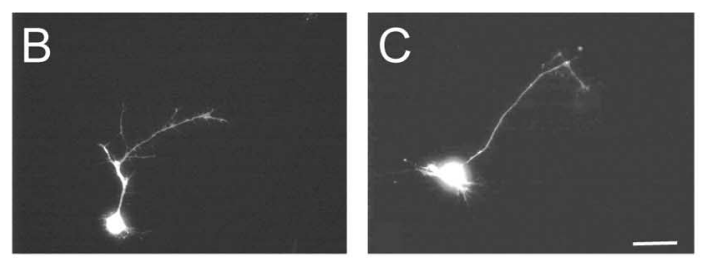

E

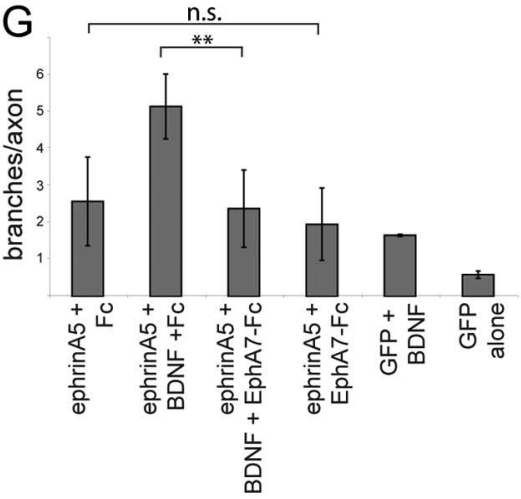

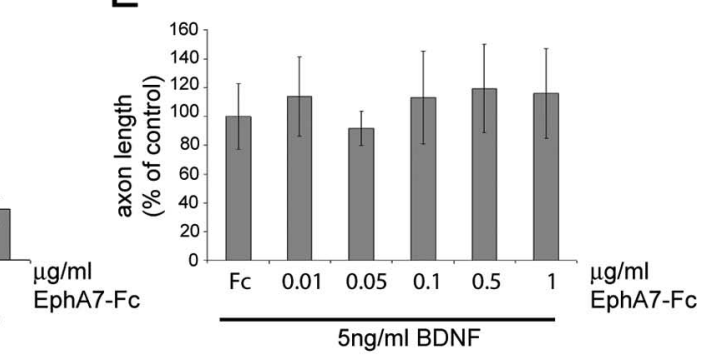

Figure 1. EphA7-Fc abolishes in a concentration-dependent manner BDNF-promoted branching of retinal axons. Single cells

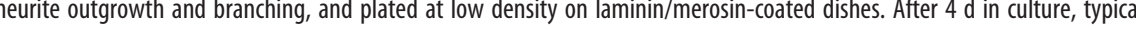
quantification of branching from three independently performed experiments with each $n>15$. $\boldsymbol{E}$, The lengths of the axons in various EphA7-Fc concentrations were not affected. Statistical analysis was performed using ANOVA. $\boldsymbol{F}$, Overexpression of eph-

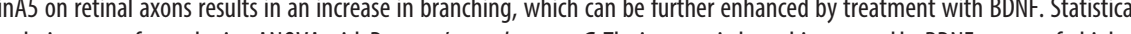
branching caused by a moderate overexpression of ephrinA5, can be abolished by treatment with EphA7-Fc $(1 \mu \mathrm{g} / \mathrm{ml})$, whereas treatment with EphA7-Fc in the absence of BDNF has no effect on branching. Analyses were done by one-way ANOVA and Tukey's

growth assay. Single cells were prepared from the nasal third of E8 chick retinas, which contain high amounts of ephrinAs (Hornberger et al., 1999), and electroporated with an eGFP expression plasmid to facilitate subsequent analysis of neurite outgrowth and branching (Fig. 1). The electroporated cells were plated at low density on laminin/merosin-coated dishes and were cultured for the next $4 \mathrm{~d}$. RGCs and their axons were identified by staining for markers expressed on retinal axons such as TrkB, Brn3A, and Thy-I (Sheppard et al., 1991; Xiang et al., 1995; Garner et al., 1996). Cells with the longest axons stained positive for these markers. The branching of retinal axons was promoted by adding $5 \mathrm{ng} / \mathrm{ml}$ BDNF after 1 and $3 \mathrm{~d}$ in vitro. The branching of retinal axons in these cultures thus followed a similar timeframe as in vivo; branching in the tectum starts from approximately E10 onward (Mey and Thanos, 1992).

To study the effects of an ephrinA activation on BDNFpromoted branching, EphA7-Fc was bath applied to the cultures at various concentrations after $2 \mathrm{~d}$, and the number of branches 

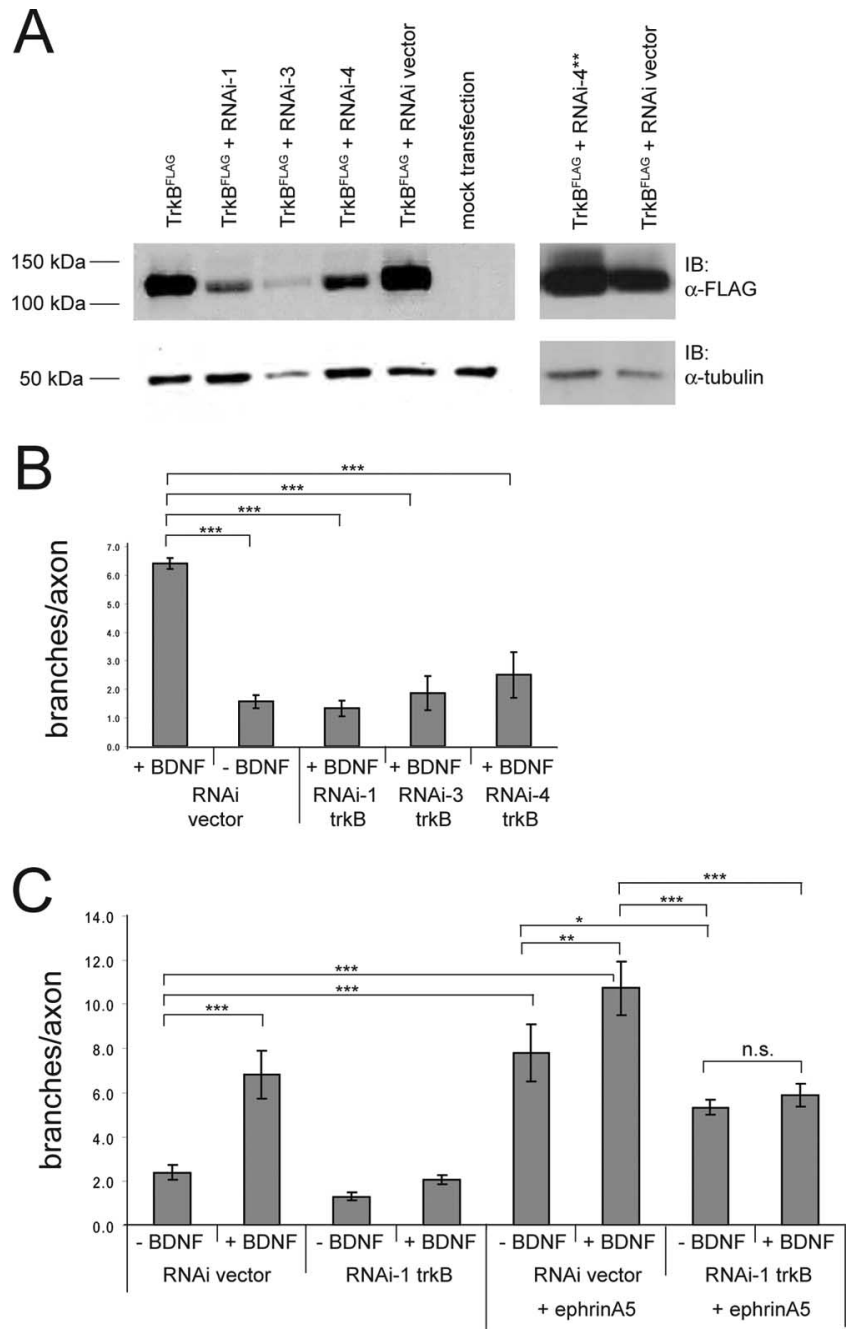

Figure 2. Downregulation of ephrinA5-evoked increase in retinal axon branching via RNAimediated knockdown of TrkB. A, CHO cells were transfected with TrkB ${ }^{\text {FLAG }}$ alone, with TrkB ${ }^{\text {FLAG }}$ and the empty RNAi vector, or with one of three different RNAi specific for TrkB. Lysates were analyzed the following day for TrkB expression levels, which were normalized by blotting with an $\alpha$-tubulin antibody. All three RNAi let to a significant downregulation of TrkB expression. RNAi with point mutations in the TrkB targeting sequence (e.g., RNAi-4**; see Materials and Methods) had no effect on TrkB expression level (right). $\boldsymbol{B}$, Abolishment of BDNF-mediated increase in retinal axon branching by expression of three different TrkB RNAi. The summary from three independent experiments is shown. Statistical analysis was performed using one-way ANOVA with Tukey's multiple-comparison test. $C$, The increase in branching mediated by ephrinA5 overexpression (see also Fig. 1) and its further increase by BDNF application can be diminished by overexpression of TrkB RNAi. The downregulation of branching is not complete, indicating that the knockdown of TrkB is not complete or that other molecules are involved in mediating the effect of ephrinA5 overexpression on branching. A reduction in branching is apparent also in the absence of BDNF, suggesting that overexpression of ephrinA5 results in a ligand-independent TrkB/ephrinA5 interaction. The summary from three independent experiments is shown. Statistical analysis was performed using one-way ANOVA with Tukey's multiple-comparison test. ${ }^{*} p=0.05 ;{ }^{* *} p=0.01 ;{ }^{* * *} p=0.001$.

per axon was determined after an additional $2 \mathrm{~d}$ in culture. Because of low-density plating, it was possible unambiguously to analyze branches emerging from individual axons, thus avoiding the inclusion of "branches" resulting from defasciculation events. Only branches $>5 \mu \mathrm{m}$ in length were included in the analysis (Simon and O'Leary, 1992). We observed that EphA7-Fc reduced, in a concentration-dependent manner, the number of branches on retinal axons (Fig. $1 A-D$ ), without having an effect on axon length (Fig. 1E). Application of control Fc had no mea- surable effect on either branch number or axon length. In contrast, in the absence of BDNF, application of EphA7-Fc did not affect the number of branches (data not shown). Thus, ephrinA activation suppresses the BDNF-dependent increase in axonal branching in a concentration-dependent manner.

Increasing the level of expression of ephrinA5 in nasal retinal axons via electroporation of an ephrinA5 expression construct led to a strong increase in the branching of retinal axons compared with retinal axons electroporated with the parental (control) plasmid (Fig. $1 F, G$ ), indicating a direct correlation between the level of expression of ephrinAs and RGC axon branching. Neurons that overexpressed ephrinA5 and were then exposed to BDNF showed an additional enhancement of branching (Fig. $1 F, G)$. The increase in branching caused by moderate overexpression of ephrinA5 in the presence of BDNF could be abolished by application of EphA7-Fc, whereas EphA7-Fc application to ephrinA-overexpressing axons in the absence of BDNF had no effect on branching (Fig. $1 G$ ).

The increase in branching mediated by ephrinA5 overexpression is at least in part dependent on TrkB, because this increased branching can be diminished by coexpression of TrkB RNAi (Fig. $2 C$ ). The RNAi used were shown in parallel experiments to downregulate $\mathrm{TrkB}$ protein expression (Fig. $2 \mathrm{~A}$ ) and to abolish the increase in branching of RGCs after application of BDNF (Fig. $2 B)$.

\section{EphA7-Fc suppresses branching of retinal axons in the stripe assay}

Is the suppression of branching by ephrinA activation a global effect through, for example, spreading of the signal along the entire axon, or is it a local effect confined to those axon regions in which ephrinAs are activated?

To distinguish between these mechanisms, we used the stripe assay technique (Fig. 3) (Walter et al., 1987; Hornberger et al., 1999) and generated alternating lanes of EphA7-Fc and Fc protein, mimicking, in a very basic way, anterior and posterior tectum, respectively. After electroporation with eGFP, single cells from $\mathrm{E} 8$ chick retinas were plated onto this substrate and incubated for $4 \mathrm{~d}$ in the presence of BDNF to promote branching of retinal axons. At high concentrations of EphA7-Fc and Fc (30 $\mu \mathrm{g} / \mathrm{ml}$ each), retinal cell bodies were found preferentially on Fc stripes, and outgrowing axons showed a preference for Fc lanes, indicating a repulsion from EphA7-Fc-containing stripes, as described previously (Rashid et al., 2005).

However, when the concentration of EphA7-Fc and Fc was decreased to $10 \mu \mathrm{g} / \mathrm{ml}$ each, cell bodies were found randomly on both types of stripes, and axons grew indiscriminately over both types of stripes. At these concentrations, therefore, EphA7-Fc is no longer repellent for axonal growth cones. We observed, however, that, under these conditions, retinal axons developed branches preferentially on Fc stripes, with little or no branching occurring on EphA7-Fc stripes (Fig. $3 A$ ). In control stripe assays with both lanes containing only Fc protein, there was no preference for branching on either stripe (Fig. $3 B$ ). Axon length was comparable on both types of stripes (EphA7-Fc/Fc and Fc/Fc; data not shown).

A quantification of three independently performed experiments showed for EphA7-Fc versus Fc stripes 1.21 branches per axon on EphA7-Fc stripes compared with 3.11 branches per axon on Fc stripes $\left({ }^{* * *} p<0.001\right.$, Student's $t$ test), whereas in parallel experiments with Fc versus Fc stripes, there were 4.51 branches per axon on the first generated stripe and 4.8 branches per axon on the second stripe (difference in branch numbers not signifi- 
cant, Student's $t$ test). A total of 71 axons for the Eph-Fc versus Fs stripe assays and 48 axons for the Fc versus Fc stripe assays were analyzed for the three independent experiments.

These data indicate that, at lower concentrations, EphA7-Fc exerts a branchsuppressing activity on retinal axons and a repellent effect on growth cone guidance only at higher concentrations. The data also suggest that, in this case, BDNFpromoted global branching can be suppressed locally, e.g., topographically, by EphA7-Fc via ephrinA reverse signaling. Thus, the branch suppression observed is a local phenomenon and is restricted to those sections of the axons in which ephri$\mathrm{nAs}$ are activated. Therefore, it is possible to reproduce in this in vitro assay the topographically specific branching seen in vivo, in which nasal retinal axons are prevented from branching in the anterior SC/tectum expressing higher amounts of EphAs (see Fig. $8 B$ ).

\section{EphrinA5 and ephrinA6 interact with all three Trks}

The local and concentration-dependent suppression of BDNFinduced branching by EphA7-Fc seen in the outgrowth and stripe assay raises the possibility that ephrinA5 and Trks either share downstream signaling pathways and/or that they directly interact at the membrane. To investigate this second possibility, we expressed full-length TrkA, TrkB, or TrkC together with FLAG-tagged ephrinA5 (ephrinA5 ${ }^{\text {FLAG }}$ ) in CHO cells. Lysates from transfected cells were immunoprecipitated using an $\alpha$ FLAG antibody, and the precipitates were then analyzed by Western blotting for the presence of the Trk proteins. We found that all three Trk receptors coimmunoprecipitated with ephrinA5 FLAG (Fig. 4A) (supplemental Fig. 1, available at www.jneurosci.org as supplemental material), as well as with ephrinA6 ${ }^{\text {FLAG }}$ (supplemental Fig. 2, available at www.jneurosci.org as supplemental material), which is also prominently expressed in the chick retinal ganglion cell layer (Menzel et al., 2001). It has to be kept in mind that transient transfection of Trks results under standard conditions in activated/phosphorylated Trk receptors (but see Fig. 5). In contrast, the PDGF receptor, another receptor tyrosine kinase, did not interact with ephrinA5 ${ }^{\mathrm{HA}}$ (Fig. $4 B$ ) (Carvalho et al., 2006).

\section{EphrinA5 and TrkB interact via CC2}

We then aimed to identify the part of TrkB that mediates the interaction with ephrinA5. A preliminary deletion analysis of rat TrkA (data not shown) led us to focus on CC2 (Perez et al., 1995). This domain is flanked $\mathrm{N}$ terminally by leucine-rich domains and on the C-terminal side by the two Ig domains comprising the neurotrophin binding site (Fig. 4C). The CC2 domain is highly conserved between TrkA, TrkB, and TrkC. We generated and analyzed FLAG-tagged versions of chick TrkB with a deletion from the $\mathrm{NH}_{2}$ terminus up to the CC2 domain (TrkB $\Delta 1^{\text {FLAG }}$ ) (Fig. $4 C)$, a deletion including part of CC2 $\left(\operatorname{TrkB} \Delta 2^{\mathrm{FLAG}}\right)$, and a deletion including the entire CC2 domain ( $\left.\operatorname{TrkB} \Delta 3^{\mathrm{FLAG}}\right)$. Thus, the difference between $\operatorname{TrkB} \Delta 1^{\mathrm{FLAG}}$ and $\operatorname{TrkB} \Delta 3^{\mathrm{FLAG}}$ is the presence or absence of the 55 amino acid long CC2 domain. There was no obvious difference in expression level and transport to the cell surface of all three deletion constructs compared with fulllength TrkB (supplemental Fig. 3, available at www.jneurosci.org as supplemental material) (data not shown).

Coimmunoprecipitation experiments in $\mathrm{CHO}$ cells showed that $\operatorname{TrkB} \Delta 1^{\text {FLAG }}$, but not $\operatorname{TrkB} \Delta 3^{\text {FLAG }}$, interacted with ephrin $A 5^{\mathrm{HA}}$, although there was still some residual binding of $\operatorname{TrkB} \Delta 2^{\text {FLAG }}$ to ephrinA5 ${ }^{\mathrm{HA}}$ (Fig. $4 D$ ). These differential interactions were observed using either the anti-HA or the anti-FLAG antibody for immunoprecipitations, that is, ephrinA $5^{\mathrm{HA}}$ precipitates contained $\operatorname{TrkB} \Delta 1^{\text {FLAG }}$ but little or no $\operatorname{TrkB} \Delta 2^{\text {FLAG }}$ or $\operatorname{TrkB} \Delta 3^{\text {FLAG }}$. In turn, $\operatorname{TrkB} \Delta 1^{\text {FLAG }}$ precipitates contained ephrinA $5^{\mathrm{HA}}$, but little ephrinA $5^{\mathrm{HA}}$ was detected in TrkB $\Delta 2^{\text {FLAG }}$ precipitates and no ephrin $5^{\mathrm{HA}}$ was present in $\operatorname{TrkB} \Delta 3^{\mathrm{FLAG}}$ precipitates (data not shown). Comparable data using similar constructs were obtained for HEK293 cells (data not shown).

Next, we cloned the CC2 domain into Robo $2^{\mathrm{FLAG}}$, which normally does not interact (i.e., in coimmunoprecipitations) with ephrinA $5^{\mathrm{HA}}$ (Fig. $4 E$ ). The CC2 domain was cloned between the fifth Ig domain and the first fibronectin type III domain (Fig. 4C) (see Materials and Methods), resulting in a chimeric Robo2$\mathrm{CC} 2{ }^{\text {FLAG }}$ protein, in which the distance between the CC2 domain and the plasma membrane is similar to that in TrkB. We found that Robo2-CC2 ${ }^{\text {FLAG }}$ also coimmunoprecipitates with ephrinA $5^{\mathrm{HA}}$ (Fig. $4 E$ ). This demonstrates that the CC2 domain is not only necessary but also sufficient for the TrkB/ephrinA5 interaction.

\section{Expression of an isolated CC2 domain in RGCs abolishes the BDNF-mediated increase in retinal axon branching}

We analyzed the effects of expressing in RGCs an isolated CC2 domain $\left(\mathrm{CC} 2{ }^{\mathrm{FLAG}}\right)$ on the ephrinA/Trk interaction, anticipating that the CC2 domain would abolish the ephrinA/Trk interaction by acting as a "dominant negative." In control experiments, we found that a fraction of CC2 $2^{\text {FLAG }}$ is secreted into the medium from transfected $\mathrm{CHO}$ cells, from which it could be immunoprecipitated (supplemental Fig. 4A, available at www.jneurosci.org as supplemental material), whereas another fraction was bound to the cell membrane or was detected in $\mathrm{CHO}$ cell lysates (supplemental Fig. $4 B$, available at www.jneurosci.org as supplemental material). 


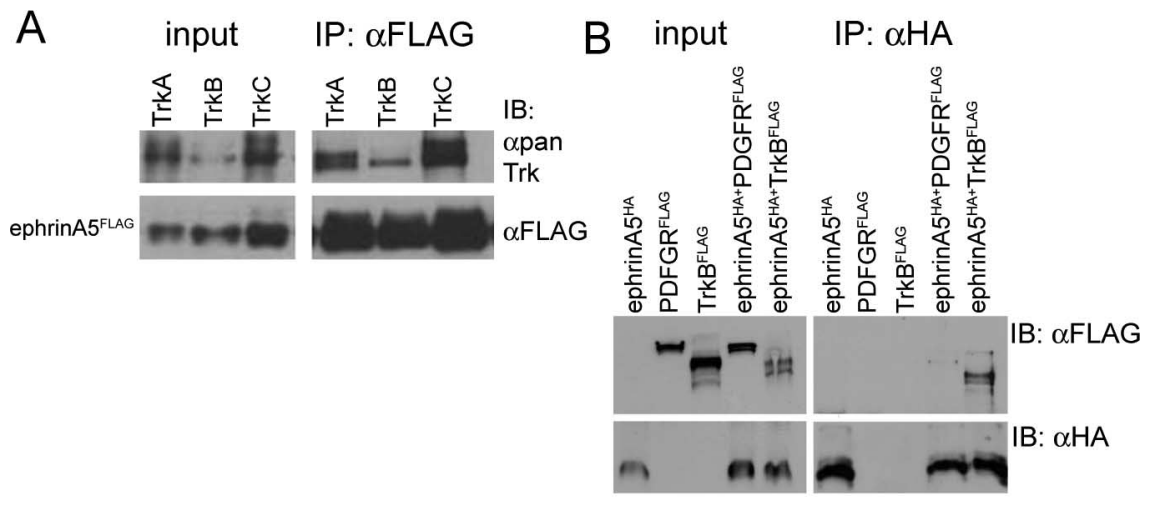

C

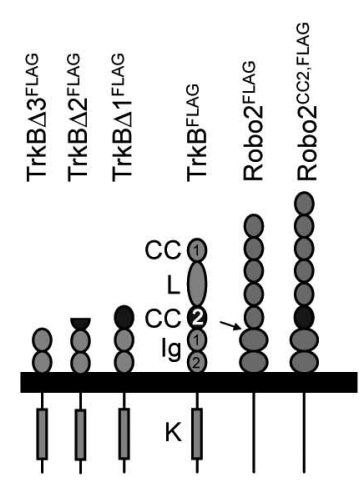

D

input IP: $\alpha H A$

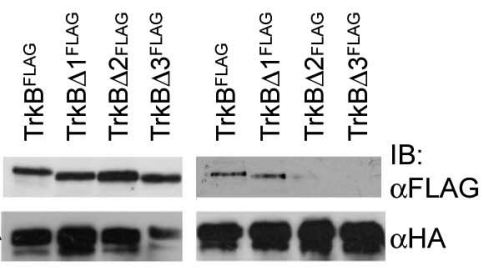

$E$
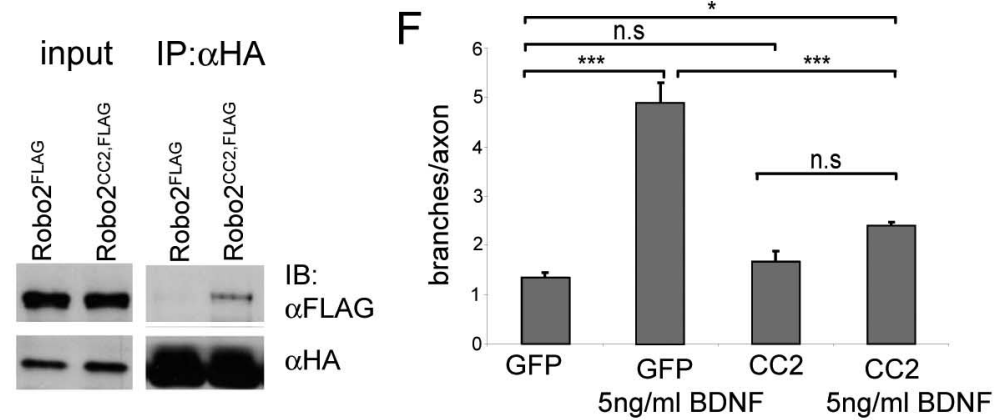

G

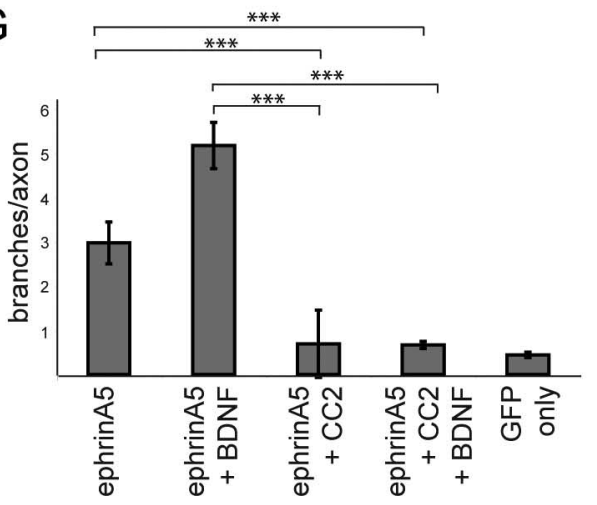

Figure 4. The $\mathrm{CC} 2$ domain of TrkB mediates the interaction with ephrinA5. Coimmunoprecipitation experiments with cell lysates from CHO cells, 1-2 d after transient transfection with expression constructs as specified below. $A$, Cotransfection of ephrinA $5^{\mathrm{FLAG}}$ with either TrkA, TrkB, or TrkC and subsequent immunoprecipitation of lysates using an $\alpha \mathrm{FLAG}$ antibody resulted in a coimmunoprecipitation of all three Trks with ephrinA $5^{\mathrm{FLAG}}$. The left shows analysis of the input that is a fraction of the $\mathrm{CHO}$ cell lysate before addition of the precipitating antibody. The right shows the analysis of immunoprecipitates (IP) using the $\alpha \mathrm{FLAG}$ antibody. The Trk receptors were detected using $\alpha$ pan-Trk antibody and ephrinA5 ${ }^{\mathrm{FLAG}}$ using the same $\alpha \mathrm{FLAG}$ antibody as used for the coimmunoprecipitation. IB, Immunoblot. $\boldsymbol{B}$, Under the same conditions, the FLAG-tagged PDGF receptor does not coimmunoprecipitate with ephrinA5 ${ }^{\mathrm{HA}}$ (Carvalho et al., 2006). C, Schematic representation of the domain structure of TrkB and of TrkB deletion mutants focusing on the $\mathrm{CC}_{2}$ domain (CC, conserved cysteine; $\mathrm{L}$, leucine-rich repeats; Ig, Ig domains; $K$, kinase domain). To the right, the domain structure of Robo2 ${ }^{\mathrm{FLAG}}$ and of Robo2- $\mathrm{CC} 2^{\mathrm{FLAG}}$ is schematized. The arrow indicates the position where the CC2 domain was inserted. D, The analysis of TrkB ${ }^{\text {FLAG }}$ deletion constructs (TrkB $\Delta 1^{\text {FLAG }}-T_{r k B} \Delta 3^{\text {FLAG }}$ in coimmunoprecipitation
We then expressed CC2 ${ }^{\text {FLAG }}$ in RGCs to study its effect on branching in the axon outgrowth assay. We found that CC2 ${ }^{\text {FLAG }}$ expression abolishes the increase in BDNF-mediated branching, whereas ectopic expression of control proteins such as eGFP had no effect on branching (Fig. $4 F)$. Likewise, the increase in branching after ephrinA5 overexpression is diminished by CC2 expression (Fig. 4G).

These data suggest that TrkB interacts with ephrinA5 on retinal ganglion cell axons via its CC2 domain. The formation of a complex between these molecules promotes retinal axon branching, whereas an abolishment of this interaction via expression of a soluble CC2 ${ }^{\text {FLAG }}$ domain abrogates the BDNF-dependent increase in branching.

\section{Neurotrophin-inducible interaction between TrkA and ephrinA5}

Next we investigated whether the interaction between Trks and ephrinAs is inducible by neurotrophins. We found that transient transfection of Trks resulted under standard conditions in activated/phosphorylated Trk receptors making such an approach unsuitable (data not shown). We therefore used PC12 cells, which endogenously express TrkA and in which the basal levels of tyrosine phosphorylation and activation of TrkA are low but can be induced by NGF treatment (Hempstead et al., 1992).

After transfection of ephrinA5 ${ }^{\text {FLAG, }}$, PC12 cells were treated with $50 \mathrm{ng} / \mathrm{ml}$ NGF for various time intervals (Fig. 5). The interaction between TrkA and ephrinA5 ${ }^{\text {FLAG }}$ was observed by immunoprecipitation of ephrinA $5^{\text {FLAG }}$ from lysates of transfected cells using an anti-

\footnotetext{
$\leftarrow$

experiments with ephrin $\mathrm{A} 5^{\mathrm{HA}}$ using an $\alpha \mathrm{HA}$-antibody showed that the $\mathrm{CC} 2$ domain is necessary for the TrkB ${ }^{\text {FLAG }}$ / ephrinA $5^{\mathrm{HA}}$ interaction. This selective interaction is observed also if using the $\alpha \mathrm{FLAG}$ antibody (to precipitate TrkB proteins) for immunoprecipitations (data not shown). E, Robo2$\mathrm{CC}^{\mathrm{FLAG}}$, but not Robo2 ${ }^{\mathrm{FLAG}}$, coimmunoprecipitates with ephrinA $5^{\mathrm{HA}}$, indicating that the $\mathrm{CC} 2$ domain is sufficient for the interaction with ephrinA $5^{\mathrm{HA}}$. $\boldsymbol{F}$, Expression of an isolated $\mathrm{CC}^{\mathrm{FLAG}}$ domain in RGCS resulted in an abolishment of the increase in BDNF-induced branching in the axon outgrowth assay, whereas expression of $C \mathrm{C}^{\mathrm{FLAG}}$ and omission of BDNF treatment had no effect on branching. Overexpression of eGFP was used in control experiments. The summary of results from three independently performed experiments is shown. Statistical analysis was performed using one-way ANOVA with Tukey's multiple-comparison test. G, The increase in branching caused by overexpression of ephrinA5 in RGCS (Fig. 1F) in the axon outgrowth assay can be abolished by expression of the $\mathrm{CC}^{\mathrm{FLAG}}$ domain. Statistical analysis was performed using one-way ANOVA with Tukey's multiplecomparison test. ${ }^{*} p=0.05 ;{ }^{* * *} p=0.001$.
} 
FLAG antibody. We found that, in the absence of NGF, TrkA was not detected in ephrinA $5{ }^{\text {FLAG }}$ precipitates, indicating a lack of interaction between nonactivated TrkAs and ephrinA5 ${ }^{\text {FLAG }}$. NGF treatment, however, led to the coimmunoprecipitation of TrkA and ephrinA5 ${ }^{\text {FLAG }}$ (Fig. 5A). This interaction was observed from $30 \mathrm{~min}$ up to $120 \mathrm{~min}$ after NGF application. Total cell lysates from the same samples were immunoblotted with anti-phosphoAkt and anti-phospho-Erk1/2 antibodies to verify NGF-induced activation of signaling cascades (Fig. 5B).

EphrinA5 binding to Trk specifically augments Akt activation Subsequently, we analyzed which of the signaling pathways of activated Trk receptors were affected through its interaction with ephrinA5 (Fig. 6) (supplemental Fig. 5, available at www. jneurosci.org as supplemental material). For this, a PC12 cell clone stably expressing ephrinA5 ${ }^{\text {FLAG }}$ was analyzed in parallel to a control PC12 cell clone (i.e., stably transfected with the parental vector only). We established the level and duration of activation of the main signaling pathways of Trks, that is, the PI-3 kinase, the PLC $\gamma$, and the MAP kinase pathways (Segal, 2003), by investigating the phosphorylation level of Akt, PLC $\gamma$, and Erk1/2, respectively. In the control PC12 cell line, application of NGF led to a rapid and sustained activation of all three pathways (Fig. 6A,B). For the ephrinA5-expressing cell line, however, the PI-3 kinase pathway upregulation was significantly stronger than in the control cell line, whereas a similar activation compared with the control cell line was seen for the MAP kinase and PLC $\gamma$ pathways (Fig. $6 A, B$ ). Similar data were also obtained using pools of PC12 cell clones stably expressing ephrinA5 (supplemental Fig. 5, available at www.jneurosci.org as supplemental material). In turn, application of EphA7-Fc led to a downregulation of pAkt signaling (Fig. 6C). A densitometric quantification of Akt phosphorylation in the presence or absence of EphA7-Fc showed that, $5 \mathrm{~min}$ after NGF treatment, phospho-Akt levels were down to $83.8 \pm$ $15.1 \%$ (mean \pm SEM) and to $39.3 \pm 9.8 \%$ (mean \pm SEM) after 30 min of NGF treatment (statistical analysis was performed by Student's $t$ test, $\left.{ }^{\star} p<0.05\right)$.

Given the correlation between PI-3 kinase signaling and axon branching (Gallo and Letourneau, 1998; Markus et al., 2002), these data fit well with the increased branching of retinal axons after augmented expression of ephrinA5 in RGCs (see above).

\section{TrkB/ephrinA interactions control synaptic plasticity in the hippocampus}

There is mounting evidence that molecules controlling axon guidance and branching are also important in synaptogenesis and synaptic plasticity at later stages of development. Thus, we were interested whether an ephrinA/TrkB interaction is involved also in these later occurring processes. For this purpose, we turned to the hippocampal system in which recent investigations have shown that ephrinAs/EphAs are involved in the control of synaptogenesis (W. Q. Gao et al., 1998; Murai et al., 2003; Martínez et al., 2005; Martínez and Soriano, 2005; Otal et al., 2006). In addition, the TrkB/BDNF system plays here a pivotal role in synapse formation (Martínez et al., 1998; Pozzo-Miller et al., 1999).

In agreement with previous studies (Martínez et al., 1998; Stein et al., 1999), RNA in situ hybridization showed that neurons in the pyramidal layer of CA1-CA3 regions coexpress ephrinA5 and TrkB transcripts at birth (postnatal day 0) (supplemental Fig. 6 , available at www.jneurosci.org as supplemental material), as well as at postnatal stages (postnatal days 5-21; data not shown). Furthermore, cultured hippocampal neurons were immunopositive for ephrinA and TrkB protein expression (Fig. 7A-C). Con-

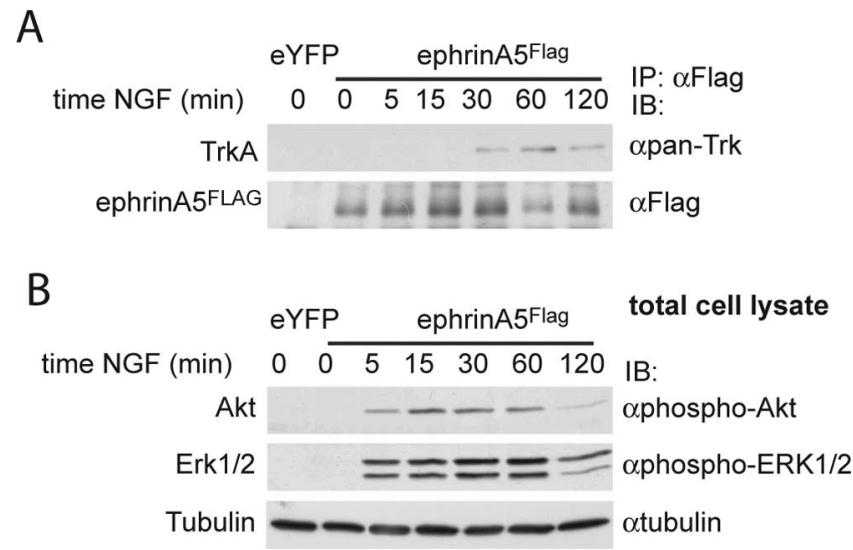

Figure 5. TrkA coprecipitates with ephrinA5 $5^{\mathrm{FLAG}}$ in PC12 cells after NGF stimulation. PC12 cells transiently transfected with ephrinA ${ }^{\mathrm{FLAG}}$ or with phosphorylated enhanced yellow fluorescent protein (eYFP) (as a control of transfection efficiency) were treated with $50 \mathrm{ng} / \mathrm{ml} \mathrm{NGF}$ for several time intervals. $A$, After immunoprecipitation of ephrinA $5^{\mathrm{FLAG}}$, the presence of TrkA in the precipitates was analyzed by Western blot, and the precipitation of ephrinA5 was verified. IB, Immunoblot; IP, immunoprecipitation. $\boldsymbol{B}$, Total cell lysates from the same samples were run to check NGF-induced activation of signaling cascades with anti-phospho-Akt and anti-phospho-Erk1/2 antibodies, and, after membrane stripping, protein loading was checked with antitubulin (bottom panels) antibodies.

focal analysis revealed the colocalization of these proteins on axons, with a particularly strong expression on growth cones (Fig. 7C). Thus, these data suggest that ephrinA5 and TrkB are coexpressed on CA1-CA3 pyramidal axons and growth cones at a time when they invade the target termination layers and form synapses.

To investigate the interactions of BDNF and ephrinA in synaptogenesis, we used long-term organotypic slice cultures, and the number of synaptic contacts was determined using electron microscopy. Our analysis focused on the CA1 stratum radiatum, which receives associational axonal input from CA3 pyramidal neurons. For these experiments, entorhinohippocampal slice cultures were prepared from newborn wild-type and eph$\operatorname{rin} A 5^{-/-}$mice. After frequent application of BDNF over the following days (see Materials and Methods), the cultures were fixed after $13 \mathrm{~d}$ in vitro, and the number of synaptic contacts in the stratum radiatum was determined using electron microscopy. As expected, BDNF treatment led to an increase in synaptic density in wild-type mice. However, the increase was significantly reduced in ephrinA5 mutant mice (Fig. $7 H$ ). The BDNF-mediated increase in synaptic density in ephrin $A 5^{-/-}$mice when compared with controls without BDNF treatment suggests that the BDNFmediated increase in synaptogenesis in the stratum radiatum is to some extent ephrinA5 independent, one possibility being that it is compensated by other ephrinAs.

We then studied the effects of EphA7-Fc on BDNF-mediated synaptogenesis in wild-type mice. EphA7-Fc affects the entire EphA system, because it binds not only ephrinA5 but almost all ephrinAs. Incubation with BDNF resulted in a $42 \%$ increase in the number of synaptic contacts in the stratum radiatum, which was significantly reduced when slices were coincubated with EphA7-Fc (Fig. 7I). We found that treatment with BSA, Fc, or EphA7-Fc without BDNF had no significant effect on the density of synaptic contacts (Fig. 7I).

These synaptogenesis data bear a close similarity to the effects of EphA7-Fc and BDNF on branching of RGC axons (Fig. 1). We therefore investigated whether branching of hippocampal neurons was affected by these molecules in a similar way to that of 


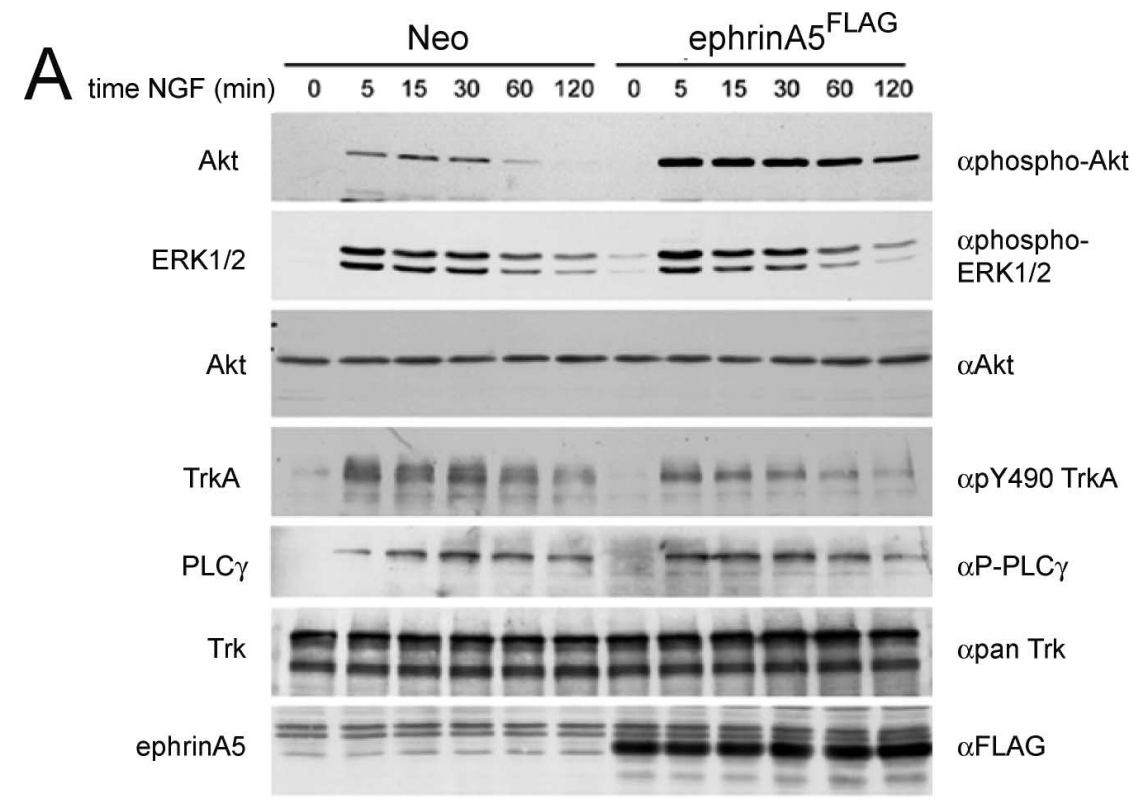

B
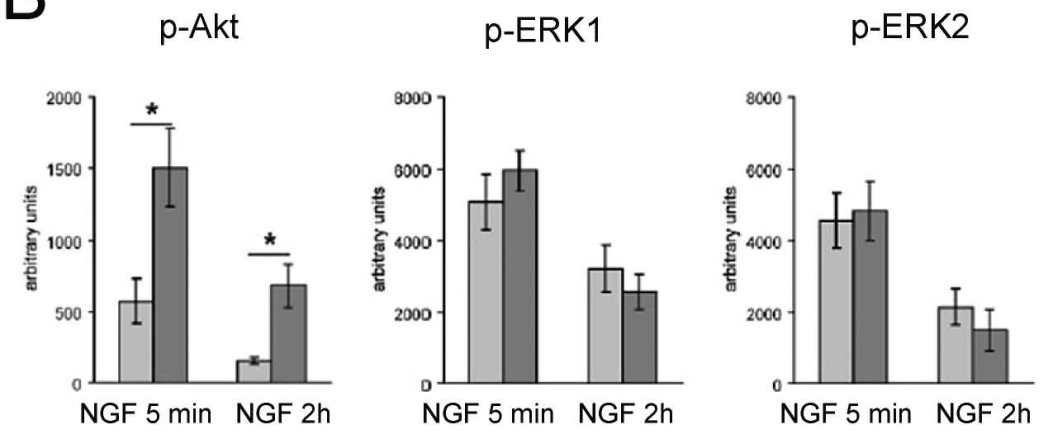

without ephrinA5

with ephrinA5

C

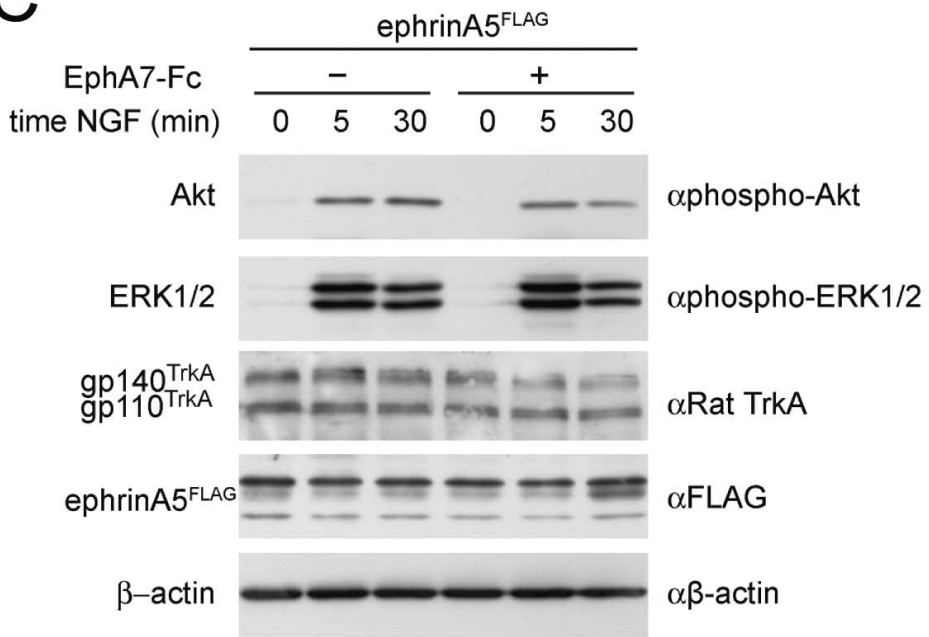

Figure 6. EphrinA5 ${ }^{\mathrm{FLAG}}$ expression in $\mathrm{PC} 12$ cells induces an additional activation of Akt after NGF treatment. $\boldsymbol{A}$, Time course experiment to compare the response to NGF of two PC12 clones stably transfected with ephrinA5 ${ }^{\text {FLAG }}$ or the empty vector (Ne0). Total cell lysates ( $40 \mu \mathrm{g}$ of protein) were analyzed by Western blot to check the status of phosphorylation of TrkA and downstream signaling molecules Akt, Erk1/2, and PLC $\gamma$ (supplemental Fig. 5, available at www.jneurosci.org as supplemental material). $\boldsymbol{B}$, Densitometric analysis of the level of phosphorylation of Akt, Erk1, and Erk2 from four independent experiments. Statistical analysis was performed by Student's $t$ test, ${ }^{*} p<0.05$. C, Effect of EphA7-Fc addition on the activation of signaling cascades by NGF. Pools of PC12 cells stably expressing ephrinA $5^{\text {FLAG }}$ were pretreated with $1 \mu \mathrm{g} / \mathrm{ml}$ of EphA7-Fc or left untreated before NGF $(100 \mathrm{ng} / \mathrm{ml})$ addition for the time periods indicated. Total cell lysates were analyzed by Western blot as described in $\boldsymbol{A}$.

RGC axons. For this purpose, hippocampal neurons from E18 rat embryos were transfected with an eGFP expression construct to facilitate later analysis of branching, plated on laminin-coated dishes, and treated in the following days with BDNF and/or EphA7-Fc using a protocol similar to that of retinal cultures. Strikingly, here again BDNF application let to an increase in axon branching that could be abolished by EphA7-Fc (Fig. 7J). Application of EphA7-Fc in the absence of BDNF did not lead to a reduction in branching (Fig. $7 J$ ). These data indicate that the same molecular players are involved in the control of axon branching and synaptogenesis of hippocampal neurons.

\section{Discussion}

In this work, we have characterized a novel cis interaction between ephrinA5 and TrkB on RGC axons. Our data suggest that this interaction contributes to the control of axon branching during development of the retinotectal projection and is also involved in branching and synaptogenesis of hippocampal neurons.

\section{EphrinA/TrkB interactions on RGCs control axon branching}

We have shown recently that ephrinAexpressing retinal axons are repelled from growing on stripes containing EphA7-Fc when given the choice between EphA7-Fc and Fc lanes (Rashid et al., 2005). We have here now investigated whether ephrinA activation by EphA7-Fc would also suppress the BDNF-promoted branching of retinal axons, because that is the key step during development of the retinotectal/ collicular projection.

Using lower concentrations of EphA7-Fc in the stripe assay than those used by Rashid et al. (2005), we observed that primary axons were no longer repelled and grew indiscriminately over both types of stripes. However, now we found a diminished branching on EphAcontaining stripes compared with control stripes (Fig. 3). Furthermore, we show that the degree of suppression of BDNFpromoted branching is sensitive to the level of activation of ephrinAs, i.e., the concentration of EphA7-Fc applied (Fig. 1). Thus, the interaction between TrkB and ephrinAs has key features of molecules involved in topographic mapping: concentration dependency and spatial restriction.

In the context of retinocollicular/tectal mapping, this leads to a model in which BDNF acts as a global branch-promoting factor and ephrinAs/EphAs suppress this 

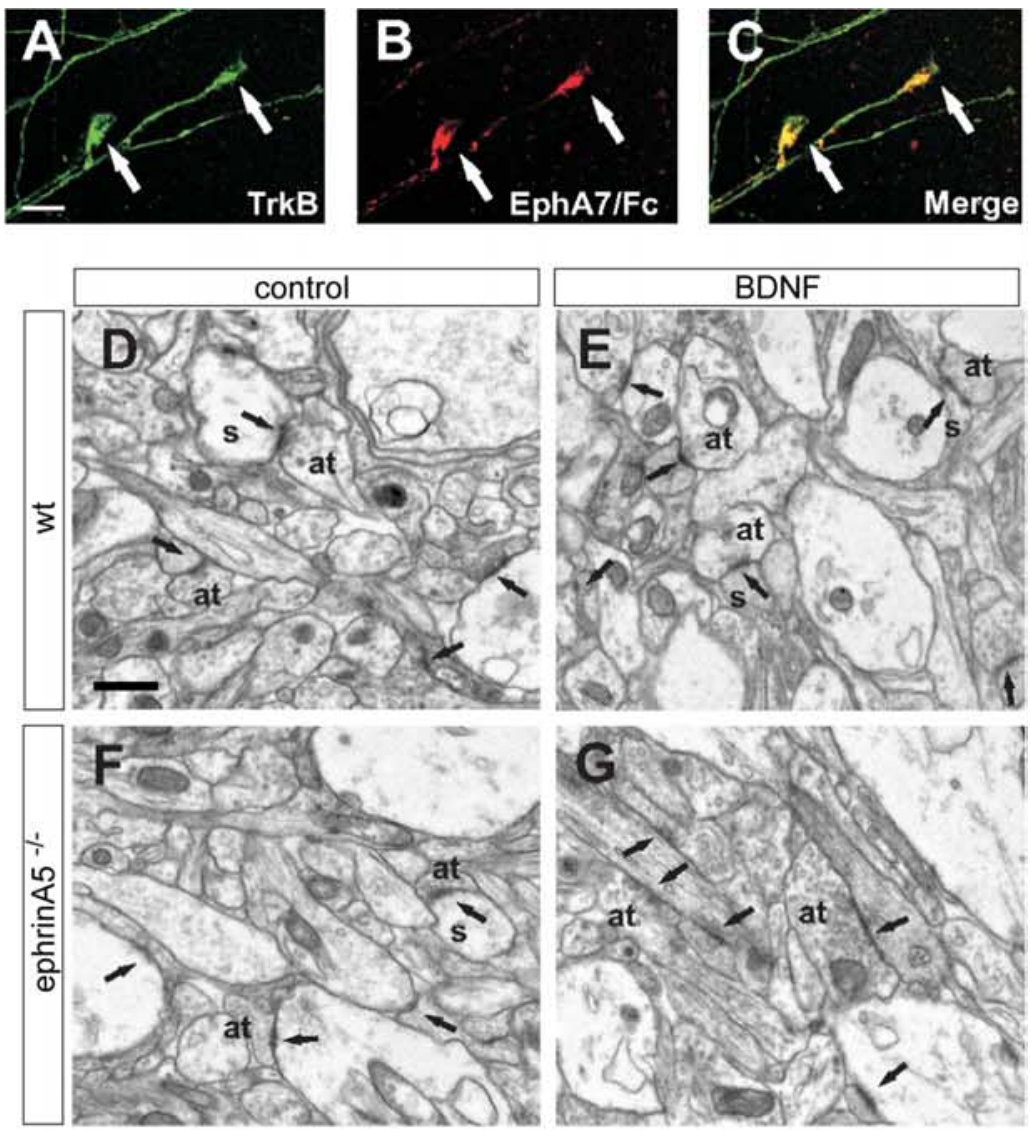

\section{H \\ density of synaptic contacts (stratum radiatum)}
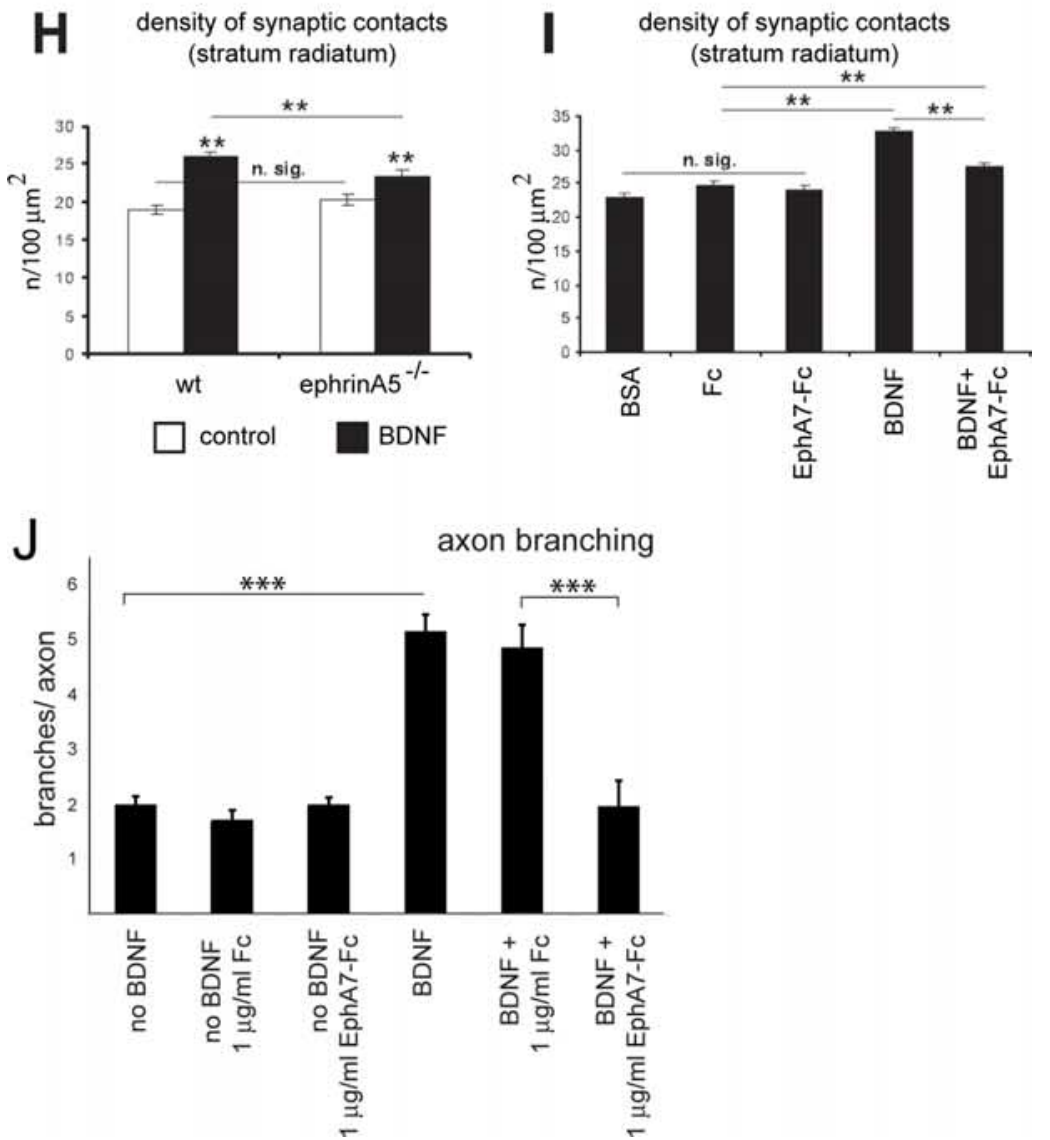

Figure 7. EphrinA5 cooperates in BDNF-induced synaptogenesis in hippocampal neurons. $\boldsymbol{A}-\boldsymbol{C}$, Double-labeling confocal images showing two examples of axonal growth cones (arrows) from hippocampal explants after $4 \mathrm{~d}$ in culture. Axonal growth cones coexpress TrkB (viewed by Alexa488-labeled antibody; $\boldsymbol{A}$ ) and ephrinAs (using EphA7-Fc and viewed by Texas Red; $\boldsymbol{B}$ ) as activity in a local manner, leading to topographically specific branching. This means that nasal axons, with higher expression of ephrinAs than temporal axons, are suppressed from branching in the anterior tectum/SC, because here high(er) expression of tectal EphAs activate axonal ephri$\mathrm{nAs}$ and abolish the BDNF-mediated branching. As a consequence, nasal axons branch only in the posterior tectum/SC (Fig. 8).

\section{Formation of local termination zones controlled by counter gradients of ephrinAs and EphAs}

Taking into account that competition between axons is involved in topographic mapping (Brown et al., 2000), we propose that individual axons branch at a position at which the suppression of BDNFpromoted branching (relative to other axons) reaches a local minimum (Fig. 8). Thus, the proximal limit of the developing termination zone would be defined by activation of axonal ephrinAs by EphAs, which are expressed in an anterior $>$ posterior gradient in the tectum/SC.

The formation of confined termination zones necessitates a counter gradient system defining the distal limit of a termination zone (Fig. $8 \mathrm{~B}$ ). It is plausible that this system also involves EphA/ephrinAs, although in this case, axonal EphAs, locally activated by a tectal anterior $<$ posterior gradient of ephrinAs, confine global Trkmediated branching. Interestingly, Ephs and Trks share a common downstream adaptor molecule, ARMS (ankyrin repeatrich membrane spanning protein) (Kong et al., 2001), which is expressed widely throughout the developing nervous system and represents an interesting candi-

\footnotetext{
$\leftarrow$

displayed in merged images (C). D-G, Electron micrographs illustrating axon terminals and synaptic contacts (arrows) in the stratum radiatum of organotypic cultures from wild-type and ephrinA5 ${ }^{-/-}$mice under control conditions ( $\boldsymbol{D}$ and $\boldsymbol{F}$, respectively) and after treatment with BDNF ( $\boldsymbol{E}$ and $\boldsymbol{G}$, respectively). $\boldsymbol{H}$, Density of synaptic contacts in the stratum radiatum of control and treated organotypic cultures from eph$\operatorname{rin} A 5^{-/-}$mice and their littermates. $I$, Histogram showing density of synaptic contacts in the stratum radiatum of $13 \mathrm{~d}$ in vitro organotypic cultures under control conditions (BSA) or treatment with $\mathrm{Fc}$, EphA7-Fc, recombinant human BDNF (BDNF), and recombinant human BDNF plus EphA7-Fc (BDNF+EphA7-Fc). Mean \pm SEM; n.sig, nonsignificant; ${ }^{* *} p<0.01$, Student's $t$ test; ${ }^{* * *} p=0.001$. at, Axon terminal; s, dendritic spine. Scale bars: $\boldsymbol{A}-\boldsymbol{C}, 10 \mu \mathrm{m} ; \mathbf{D}-\mathbf{G}, 0.5 \mu \mathrm{m}$. $J$, EphA7-Fc treatment abolishes the BDNF-induced branching of hippocampal neurons. Using a protocol described in experiments documented in Figure 1, hippocampal neurons were treated for $2 \mathrm{~d}$ under various conditions as indicated.
} 

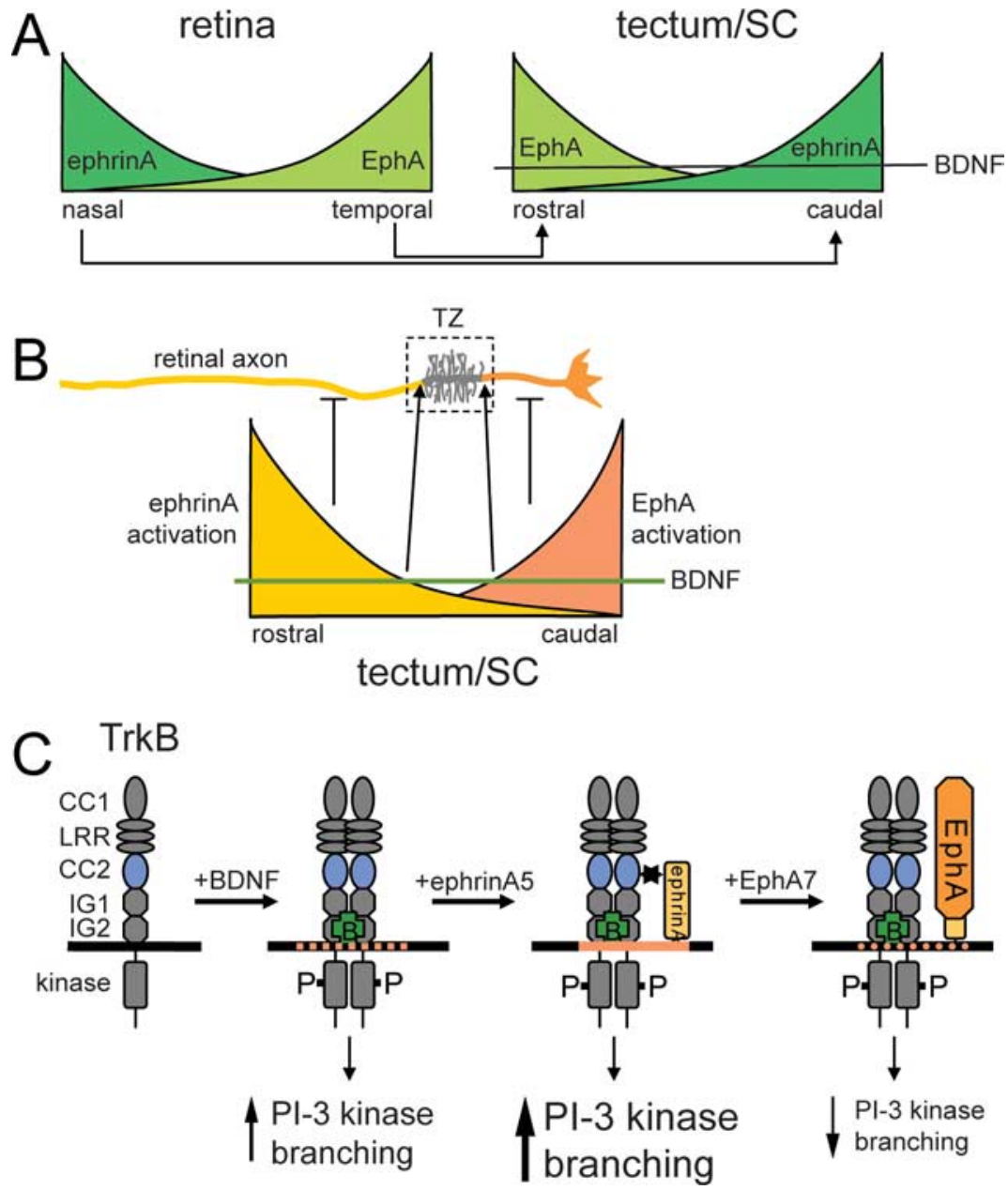

Figure 8. Model for the topographic branching of retinal axons in the tectum/ $\mathrm{SC}$ based on an interaction between ephrinAs and TrkB. $A$, Schematic expression pattern of EphAs and ephrinAs in the retina (left) and tectum/SC (right). BDNF is uniformly expressed in the tectum/SC and promotes branching of retinal axons globally via TrkB. The axonal projection pattern is indicated with nasal axons projecting onto the posterior tectum $/ \mathrm{SC}$ and temporal axons onto the anterior tectum $/ \mathrm{SC} . \boldsymbol{B}$, EphAs and ephrinAs, as well as TrkB receptors, are uniformly distributed over the entire length of the axon. Local activation of ephrinAs on retinal axons in the proximal part of the axon and of EphAs in the distal part of the axon, causing a corresponding local suppression of branching resulting in the formation of a termination zone in that part of the axon in which branch suppression is minimal. Suppression anterior to the termination zone: ephrinAs are activated locally by tectally expressed EphAs. Activated ephrinAs in turn abolish BDNF-mediated branching. Because of the anterior $>$ posterior gradient of EphAs, branch suppression occurs anterior (proximal) to the termination zone. Suppression posterior to the termination zone: it appears plausible that this activity is controlled by gradients of ephrinAs in the posterior tectum/SC (Yates et al., 2001), which activate retinal EphA receptors and which might interfere with TrkB signaling (Kong et al., 2001; Fitzgerald et al., 2008). C, Effects of ephrin/TrkB interactions on retinal axon branching. Binding of BDNF to TrkB results in its activation and tyrosine phosphorylation and leads via activation of, in particular, Pl-3 kinase signaling to an increase in branching. Interaction of activated TrkB with ephrinAs (possibly in lipid rafts; orange) augments PI-3 kinase signaling and branching. Activation of ephrinAs by EphAs diminishes branching and a reduction in pAkt signaling.

date as an integrator of Trk/Eph-controlled branching (Fitzgerald et al., 2008).

\section{The CC2 domain of TrkB mediates the interaction with ephrinAs}

Interestingly, the ephrin $\mathrm{A} / \mathrm{TrkB}$ interaction has two features: in the absence of activation of ephrinAs (by EphA molecules), the BDNF-dependent ephrinA/TrkB interaction promotes axon branching, whereas ephrinA activation (by EphA7-Fc) results in a suppression of branching.

We addressed whether it is the interaction between ephrinAs and TrkB at the cell membrane that controls the level of RGC axon branching but not, for example, a cross regulation of converging signaling pathways downstream of ephrinAs and TrkB.
The analysis of a deletion series and of chimeric proteins led us to identify the CC2 domain in TrkB (Perez et al., 1995) as the domain necessary and sufficient for its interaction with ephrinA5 (Fig. 4). In particular, a chimeric protein of Robo 2 and the CC2 domain binds to ephrinA5, whereas the wild-type form of Robo2 does not. We then showed that an isolated CC2 domain can act as a dominant negative (likely as a result of a disruption of the ephrinA/TrkB interaction), because the overexpression of CC2 in retinal axons results in an abolishment of the BDNF-induced increase in retinal branching. Intriguingly, also the increase in branching caused by overexpression of ephrinA5 could be blocked by a simultaneous expression of CC2.

The CC2 overexpression experiments provide good evidence that it is the interplay between ephrinAs and TrkB at the cell membrane that controls retinal axon branching.

The CC2 domain together with the leucine-rich repeats and the $\mathrm{NH}_{2}$-terminal $\mathrm{CC} 1$ domain form the evolutionary most conserved part between all three Trks (Benito-Gutiérrez et al., 2006). This might explain why ephrinA5 and ephrinA6 (and possibly other ephrinAs) interact with all three Trks (Fig. 4) (supplemental Fig. 2, available at www.jneurosci.org as supplemental material). To date, there have been few other reports on the role of the CC2 domain in Trk function. The neurotrophin receptors are, however, known to interact with some other receptor systems (Chao, 2003).

\section{The ephrinA/Trk interaction further augments the PI-3 kinase pathway} We found that the Trk/ephrinA5 interaction is induced by neurotrophins (Fig. 5) and results in a preferential activation of the PI-3 kinase/Akt pathway (Fig. 6). The two other main TrkB signaling pathways, MAP kinase and PLC $\gamma$, were not enhanced when compared with Trk signaling in the absence of ephrinAs. In a complementary set of experiments, we show that treatment of TrkB/ephrinA5expressing cells with EphA7-Fc resulted in a decreased phosphoAkt output (Fig. 6).

Interestingly, other investigations have shown that TrkAmediated increase in axon branching occurs specifically via PI-3 kinase and Akt activation (Gallo and Letourneau, 1998; Markus et al., 2002). In agreement with this, we propose that the ephrinA5/TrkB complex controls retinal axon branching via PI-3 kinase signaling. Thus, an increase in ephrinA5 expression leads to higher PI-3 kinase signaling and an increase in BDNFmediated branching, whereas EphA7-Fc treatment (and activation of ephrinAs) leads to a reduction in PI-3 kinase signaling as well as a reduction in axon branching (Figs. 6, 8).

A target of PI-3 kinase is GSK3 $\beta$, a central control element in 
regulating cytoskeletal dynamics during axon branching and guidance (Zhou and Snider, 2005). Axonal expression of a dominant-negative form of GSK $3 \beta$ disturbs the development of the retinotectal projection in zebrafish. Here the number of added branches was decreased, whereas that of eliminated branches was not changed (Tokuoka et al., 2002). Interestingly, TrkB signaling also promotes branch addition but not their elimination (Cohen-Cory, 1999). These links strongly implicate that the PI-3 kinase pathway is the main pathway by which ephrinA5/ TrkB complexes promote branching.

\section{A possible role of membrane microdomains in TrkB/ephrinA interactions}

Binding of BDNF to TrkB results in a shift of TrkB into a special, lipid raft-like, membrane microenvironment (Bilderback et al., 1999; C. S. Huang et al., 1999; Guirland et al., 2004; Suzuki et al., 2004). Signaling from within this special lipid environment is crucial for at least some TrkB functions, because the pharmacological disruption of raft-like structures abolishes BDNFmediated axon guidance (Guirland et al., 2004). It has been proposed that these lipid microdomains function through their capacity to promote certain protein-protein interactions but prevent others, leading to the establishment of a different signaling environment in rafts versus nonrafts (Simons and Toomre, 2001). This kind of regulation appears to be a common phenomenon because other receptor tyrosine kinases such as c-Ret also have been shown to have different signaling properties dependent on their location inside versus outside of raft-like structures (Tansey et al., 2000; Paratcha et al., 2001).

This concept implies that mechanisms/molecules that shift TrkB into raft-like structures or promote longer TrkB residence in this environment will have an impact on the signaling of TrkB. EphrinAs are GPI-anchored molecules and therefore reside in rafts (Davy et al., 1999; Huai and Drescher, 2001). Thus, a BDNFinduced shift of TrkBs into rafts could result in the "capture" of TrkBs by ephrinAs and lead to an increased residence of TrkB in these domains. This in turn would affect its signaling, and indeed we have observed a specific increase in PI-3 kinase signaling (Fig. 5). Interestingly, the substrate of PI-3 kinase, phosphatidylinositol-4, 5-biphosphate, is particularly enriched in lipid rafts (Golub et al., 2004); thus, the anticipated increased residence of ephrinA5/ TrkB complexes in rafts correlates well with the augmentation of this particular signaling pathway.

\section{EphrinA5/Trk interaction in synaptic plasticity}

It has been proposed that molecules controlling the guidance and branching of axons using attractive and repellent mechanisms might contribute at later stages to the formation, stabilization, and elimination of synapses as well as the control of synaptic plasticity. Studies in the retinotectal projection, for example, have shown that branching and synaptogenesis are closely connected and interdependent (Meyer and Smith, 2006; Ruthazer et al., 2006).

On a molecular level, prominent candidates for such dual roles include members of the Wnt family (Ciani and Salinas, 2005), slits (Campbell et al., 2007), FGFs (Szebenyi et al., 2001; Umemori et al., 2004), and, in particular, BDNF, which is involved not only in axon branching but also in synaptogenesis, synapse stabilization, and activity-dependent synaptic plasticity (Figurov et al., 1996; Martínez et al., 1998; Z. J. Huang et al., 1999; Alsina et al., 2001; Meyer and Smith, 2006; Ruthazer et al., 2006). Moreover, although there is ample evidence for a role of the EphB subfamily in axonal branching and synaptic plasticity, less is known about that of the EphA subfamily (P. P. Gao et al., 1998; W. Q. Gao et al., 1998; Murai et al., 2003; Klein, 2004; Martínez et al., 2005; Martínez and Soriano, 2005; Otal et al., 2006).

However, members of the EphA class are prominently expressed in regions undergoing synaptogenesis and synaptic plasticity, and ephrinA/EphA members have been shown to be regulated by activity and after lesion (Knöll et al., 2001b; Xu et al., 2003; Wang et al., 2005; Serizawa et al., 2006). Moreover, ephri$\mathrm{nAs}$ and neural activity act together to regulate the patterning of retinocollicular and retinogeniculate connections (Pfeiffenberger et al., 2005).

Therefore, we characterized the TrkB/ephrinA interaction in hippocampal neuronal cultures to investigate axon branching but used hippocampal organotypic cocultures to study synaptogenesis (Marty et al., 2000). We could show for both assay systems that the BDNF-mediated increase in branching or synapse density could be antagonized by application of EphA7-Fc. Moreover, the increase in synapse density in ephrinA5 mutant mice was reduced after BDNF application when compared with wild-type mice (Fig. 7).

These data correlate very well with our results obtained from an analysis of branching of RGC axons and suggest that, in addition to branching, also synaptogenesis in the retinotectal system is under control of an ephrinA/TrkB interplay.

Overall, our findings support the concept that the same molecular players, here Trks and ephrinAs, control axon branching and synaptogenesis/synaptic plasticity in multiple parts of the brain. An important aspect in the near future will be to determine more closely the role of neural activity in these interactions.

\section{References}

Alsina B, Vu T, Cohen-Cory S (2001) Visualizing synapse formation in arborizing optic axons in vivo: dynamics and modulation by BDNF. Nat Neurosci 4:1093-1101.

Benito-Gutiérrez E, Garcia-Fernàndez J, Comella JX (2006) Origin and evolution of the Trk family of neurotrophic receptors. Mol Cell Neurosci 31:179-192.

Bilderback TR, Gazula VR, Lisanti MP, Dobrowsky RT (1999) Caveolin interacts with Trk A and p75(NTR) and regulates neurotrophin signaling pathways. J Biol Chem 274:257-263.

Brown A, Yates PA, Burrola P, Ortuño D, Vaidya A, Jessell TM, Pfaff SL, O'Leary DD, Lemke G (2000) Topographic mapping from the retina to the midbrain is controlled by relative but not absolute levels of EphA receptor signaling. Cell 102:77-88.

Campbell DS, Stringham SA, Timm A, Xiao T, Law MY, Baier H, Nonet ML, Chien CB (2007) Slitla inhibits retinal ganglion cell arborization and synaptogenesis via Robo2-dependent and -independent pathways. Neuron 55:231-245.

Carvalho RF, Beutler M, Marler KJ, Knöll B, Becker-Barroso E, Heintzmann R, Ng T, Drescher U (2006) Silencing of EphA3 through a cis interaction with ephrinA5. Nat Neurosci 9:322-330.

Chao MV (2003) Neurotrophins and their receptors: a convergence point for many signalling pathways. Nat Rev Neurosci 4:299-309.

Ciani L, Salinas PC (2005) WNTs in the vertebrate nervous system: from patterning to neuronal connectivity. Nat Rev Neurosci 6:351-362.

Cohen-Cory S (1999) BDNF modulates, but does not mediate, activitydependent branching and remodeling of optic axon arbors in vivo. J Neurosci 19:9996-10003.

Cohen-Cory S, Fraser SE (1995) Effects of brain-derived neurotrophic factor on optic axon branching and remodelling in vivo. Nature 378:192-196.

Das RM, Van Hateren NJ, Howell GR, Farrell ER, Bangs FK, Porteous VC, Manning EM, McGrew MJ, Ohyama K, Sacco MA, Halley PA, Sang HM, Storey KG, Placzek M, Tickle C, Nair VK, Wilson SA (2006) A robust system for RNA interference in the chicken using a modified microRNA operon. Dev Biol 294:554-563.

Davy A, Gale NW, Murray EW, Klinghoffer RA, Soriano P, Feuerstein C, Robbins SM (1999) Compartmentalized signaling by GPI-anchored 
ephrinA5 requires the fyn tyrosine kinase to regulate cellular adhesion. Genes Dev 13:3125-3135.

Del Río JA, Heimrich B, Borrell V, Förster E, Drakew A, Alcántara S, Nakajima K, Miyata T, Ogawa M, Mikoshiba K, Derer P, Frotscher M, Soriano E (1997) A role for Cajal-Retzius cells and reelin in the development of hippocampal connections. Nature 385:70-74.

Egea J, Nissen UV, Dufour A, Sahin M, Greer P, Kullander K, Mrsic-Flogel TD, Greenberg ME, Kiehn O, Vanderhaeghen P, Klein R (2005) Regulation of EphA 4 kinase activity is required for a subset of axon guidance decisions suggesting a key role for receptor clustering in Eph function. Neuron 47:515-528.

Figurov A, Pozzo-Miller LD, Olafsson P, Wang T, Lu B (1996) Regulation of synaptic responses to high-frequency stimulation and LTP by neurotrophins in the hippocampus. Nature 381:706-709.

Fitzgerald M, Buckley A, Lukehurst SS, Dunlop SA, Beazley LD, Rodger J (2008) Neurite responses to ephrin-A5 modulated by BDNF: Evidence for TrkBEphA interactions. Biochem Biophys Res Commun 374:625-630.

Gallo G, Letourneau PC (1998) Localized sources of neurotrophins initiate axon collateral sprouting. J Neurosci 18:5403-5414.

Gao PP, Yue Y, Zhang JH, Cerretti DP, Levitt P, Zhou R (1998) Regulation of thalamic neurite outgrowth by the Eph ligand ephrin-A5: implications in the development of thalamocortical projections. Proc Natl Acad Sci USA 95:5329-5334.

Gao WQ, Shinsky N, Armanini MP, Moran P, Zheng JL, Mendoza-Ramirez JL, Phillips HS, Winslow JW, Caras IW (1998) Regulation of hippocampal synaptic plasticity by the tyrosine kinase receptor, REK7/EphA5, and its ligand, AL-1/Ephrin-A5. Mol Cell Neurosci 11:247-259.

Garner AS, Menegay HJ, Boeshore KL, Xie XY, Voci JM, Johnson JE, Large TH (1996) Expression of TrkB receptor isoforms in the developing avian visual system. J Neurosci 16:1740-1752.

Golub T, Wacha S, Caroni P (2004) Spatial and temporal control of signaling through lipid rafts. Curr Opin Neurobiol 14:542-550.

Guirland C, Suzuki S, Kojima M, Lu B, Zheng JQ (2004) Lipid rafts mediate chemotropic guidance of nerve growth cones. Neuron 42:51-62.

Hempstead BL, Rabin SJ, Kaplan L, Reid S, Parada LF, Kaplan DR (1992) Overexpression of the trk tyrosine kinase rapidly accelerates nerve growth factor-induced differentiation. Neuron 9:883-896.

Hivert B, Liu Z, Chuang CY, Doherty P, Sundaresan V (2002) Robol and robo2 are homophilic binding molecules that promote axonal growth. Mol Cell Neurosci 21:534-545.

Hornberger MR, Dütting D, Ciossek T, Yamada T, Handwerker C, Lang S, Weth F, Huf J, Wessel R, Logan C, Tanaka H, Drescher U (1999) Modulation of EphA receptor function by coexpressed ephrinA ligands on retinal ganglion cell axons. Neuron 22:731-742.

Huai J, Drescher U (2001) An ephrinA-dependent signaling pathway controls integrin function and is linked to the tyrosine phosphorylation of a $120 \mathrm{kDa}$ protein. J Biol Chem 276:6689-6694.

Huang CS, Zhou J, Feng AK, Lynch CC, Klumperman J, DeArmond SJ, Mobley WC (1999) Nerve growth factor signaling in caveolae-like domains at the plasma membrane. J Biol Chem 274:36707-36714.

Huang ZJ, Kirkwood A, Pizzorusso T, Porciatti V, Morales B, Bear MF, Maffei L, Tonegawa S (1999) BDNF regulates the maturation of inhibition and the critical period of plasticity in mouse visual cortex. Cell 98:739-755.

Klein R (2004) Eph/ephrin signaling in morphogenesis, neural development and plasticity. Curr Opin Cell Biol 16:580-589.

Knöll B, Zarbalis Z, Wurst W, Drescher U (2001a) A role for the EphA family in the topographic targeting of vomeronasal axons. Development 128:895-906.

Knöll B, Isenmann S, Kilic E, Walkenhorst J, Engel S, Wehinger J, Bähr M, Drescher U (2001b) Graded expression patterns of ephrin-As in the superior colliculus after lesion of the adult mouse optic nerve. Mech Dev 106:119-127.

Kong H, Boulter J, Weber JL, Lai C, Chao MV (2001) An evolutionarily conserved transmembrane protein that is a novel downstream target of neurotrophin and ephrin receptors. J Neurosci 21:176-185.

Markus A, Zhong J, Snider WD (2002) Raf and akt mediate distinct aspects of sensory axon growth. Neuron 35:65-76.

Martínez A, Soriano E (2005) Functions of ephrin/Eph interactions in the development of the nervous system: emphasis on the hippocampal system. Brain Res Brain Res Rev 49:211-226.

Martínez A, Alcántara S, Borrell V, Del Río JA, Blasi J, Otal R, Campos N, Boronat A, Barbacid M, Silos-Santiago I, Soriano E (1998) TrkB and
TrkC signaling are required for maturation and synaptogenesis of hippocampal connections. J Neurosci 18:7336-7350.

Martínez A, Otal R, Sieber BA, Ibáñez C, Soriano E (2005) Disruption of ephrin-A/EphA binding alters synaptogenesis and neural connectivity in the hippocampus. Neuroscience 135:451-461.

Marty S, Wehrlé R, Sotelo C (2000) Neuronal activity and brain-derived neurotrophic factor regulate the density of inhibitory synapses in organotypic slice cultures of postnatal hippocampus. J Neurosci 20:8087-8095.

McLaughlin T, O'Leary DD (2005) Molecular gradients and development of retinotopic maps. Annu Rev Neurosci 28:327-355.

Menzel P, Valencia F, Godement P, Dodelet VC, Pasquale EB (2001) Ephrin-A6, a new ligand for EphA receptors in the developing visual system. Dev Biol 230:74-88.

Mey J, Thanos S (1992) Development of the visual system of the chick: a review. J Hirnforsch 33:673-702.

Meyer MP, Smith SJ (2006) Evidence from in vivo imaging that synaptogenesis guides the growth and branching of axonal arbors by two distinct mechanisms. J Neurosci 26:3604-3614.

Meyer-Franke A, Kaplan MR, Pfrieger FW, Barres BA (1995) Characterization of the signaling interactions that promote the survival and growth of developing retinal ganglion cells in culture. Neuron 15:805-819.

Meyer-Franke A, Wilkinson GA, Kruttgen A, Hu M, Munro E, Hanson MG Jr, Reichardt LF, Barres BA (1998) Depolarization and cAMP elevation rapidly recruit TrkB to the plasma membrane of CNS neurons. Neuron 21:681-693.

Murai KK, Nguyen LN, Irie F, Yamaguchi Y, Pasquale EB (2003) Control of hippocampal dendritic spine morphology through ephrin-A3/EphA4 signaling. Nat Neurosci 6:153-160.

Nakamura H, O'Leary DDM (1989) Inaccuracies in initial growth and arborization of chick retinotectal axons followed by course corrections and axon remodeling to develop retinotectal order. J Neurosci 9:3776-3795.

Otal R, Burgaya F, Frisén J, Soriano E, Martínez A (2006) Ephrin-A5 modulates the topographic mapping and connectivity of commissural axons in murine hippocampus. Neuroscience 141:109-121.

Paratcha G, Ledda F, Baars L, Coulpier M, Besset V, Anders J, Scott R, Ibáñez CF (2001) Released GFRalphal potentiates downstream signaling, neuronal survival, and differentiation via a novel mechanism of recruitment of c-Ret to lipid rafts. Neuron 29:171-184.

Pérez P, Coll PM, Hempstead BL, Martín-Zanca D, Chao MV (1995) NGF binding to the trk tyrosine kinase receptor requires the extracellular immunoglobulin-like domains. Mol Cell Neurosci 6:97-105.

Pfeiffenberger C, Cutforth T, Woods G, Yamada J, Rentería RC, Copenhagen DR, Flanagan JG, Feldheim DA (2005) Ephrin-As and neural activity are required for eye-specific patterning during retinogeniculate mapping. Nat Neurosci 8:1022-1027.

Pozzo-Miller LD, Gottschalk W, Zhang L, McDermott K, Du J, Gopalakrishnan R, Oho C, Sheng ZH, Lu B (1999) Impairments in high-frequency transmission, synaptic vesicle docking, and synaptic protein distribution in the hippocampus of BDNF knock-out mice. J Neurosci 19:4972-4983.

Rashid T, Upton AL, Blentic A, Ciossek T, Knöll B, Thompson ID, Drescher U (2005) Opposing gradients of Ephrin-As and EphA7 in the superior colliculus are essential for topographic mapping in the mammalian visual system. Neuron 47:57-69.

Reichardt LF (2006) Neurotrophin-regulated signalling pathways. Philos Trans R Soc Lond B Biol Sci 361:1545-1564.

Ruthazer ES, Cline HT (2004) Insights into activity-dependent map formation from the retinotectal system: a middle-of-the-brain perspective. J Neurobiol 59:134-146.

Ruthazer ES, Li J, Cline HT (2006) Stabilization of axon branch dynamics by synaptic maturation. J Neurosci 26:3594-3603.

Segal RA (2003) Selectivity in neurotrophin signaling: theme and variations. Annu Rev Neurosci 26:299-330.

Serizawa S, Miyamichi K, Takeuchi H, Yamagishi Y, Suzuki M, Sakano H (2006) A neuronal identity code for the odorant receptor-specific and activity-dependent axon sorting. Cell 127:1057-1069.

Sheppard AM, Konopka M, Robinson SR, Morgan IG, Jeffrey PL (1991) Thy-1 antigen is specific to ganglion cells in chicks. Neurosci Lett 123:87-90.

Simon DK, O'Leary DDM (1992) Development of topographic order in the mammalian retinocollicular projection. J Neurosci 12:1212-1232.

Simons K, Toomre D (2000) Lipid rafts and signal transduction. Nat Rev Mol Cell Biol 1:31-39. 
Stein E, Savaskan NE, Ninnemann O, Nitsch R, Zhou R, Skutella T (1999) A role for the Eph ligand ephrin-A3 in entorhino-hippocampal axon targeting. J Neurosci 19:8885-8893.

Stoppini L, Buchs PA, Muller D (1991) A simple method for organotypic cultures of nervous tissue. J Neurosci Methods 37:173-182.

Suzuki S, Numakawa T, Shimazu K, Koshimizu H, Hara T, Hatanaka H, Mei L, Lu B, Kojima M (2004) BDNF-induced recruitment of TrkB receptor into neuronal lipid rafts: roles in synaptic modulation. J Cell Biol 167:1205-1215.

Szebenyi G, Dent EW, Callaway JL, Seys C, Lueth H, Kalil K (2001) Fibroblast growth factor-2 promotes axon branching of cortical neurons by influencing morphology and behavior of the primary growth cone. J Neurosci 21:3932-3941.

Tansey MG, Baloh RH, Milbrandt J, Johnson EM Jr (2000) GFRalphamediated localization of RET to lipid rafts is required for effective downstream signaling, differentiation, and neuronal survival. Neuron 25:611-623.

Tokuoka H, Yoshida T, Matsuda N, Mishina M (2002) Regulation by glycogen synthase kinase- $3 \beta$ of the arborization field and maturation of retinotectal projection in zebrafish. J Neurosci 22:10324-10332.

Umemori H, Linhoff MW, Ornitz DM, Sanes JR (2004) FGF22 and its close relatives are presynaptic organizing molecules in the mammalian brain. Cell 118:257-270.

Walter J, Kern-Veits B, Huf J, Stolze B, Bonhoeffer F (1987) Recognition of position-specific properties of tectal cell membranes by retinal axons in vitro. Development 101:685-696.

Wang Y, Ni ZM, Zhou CF (2005) Denervation-induced spatiotemporal upregulation of ephrin-A2 in the mouse hippocampus after transections of the perforant path. FEBS Lett 579:1055-1060.

Xiang M, Zhou L, Macke JP, Yoshioka T, Hendry SH, Eddy RL, Shows TB, Nathans J (1995) The Brn-3 family of POU-domain factors: primary structure, binding specificity, and expression in subsets of retinal ganglion cells and somatosensory neurons. J Neurosci 15:4762-4785.

Xu B, Li S, Brown A, Gerlai R, Fahnestock M, Racine RJ (2003) EphA/ ephrin-A interactions regulate epileptogenesis and activity-dependent axonal sprouting in adult rats. Mol Cell Neurosci 24:984-999.

Yates PA, Roskies AL, McLaughlin T, O'Leary D (2001) Topographicspecific axon branching controlled by ephrin-As is the critical event in retinotectal map development. J Neurosci 21:8548-8563.

Zhou FQ, Snider WD (2005) Cell biology. GSK-3beta and microtubule assembly in axons. Science 308:211-214. 